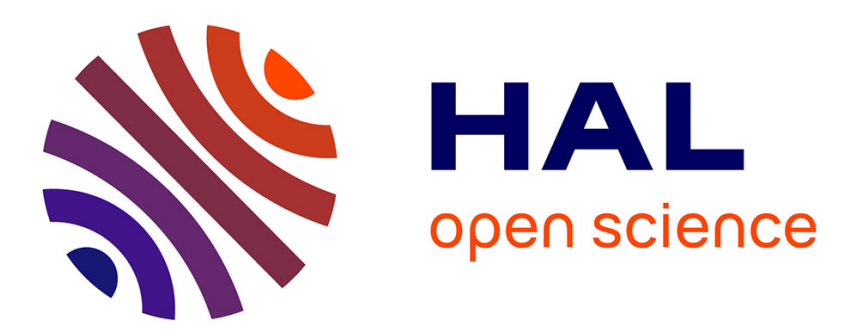

\title{
Plasma assisted combustion of methane-air mixtures: Validation and reduction
}

\author{
L. Cheng, N. Barleon, B. Cuenot, O. Vermorel, A. Bourdon
}

\section{To cite this version:}

L. Cheng, N. Barleon, B. Cuenot, O. Vermorel, A. Bourdon. Plasma assisted combustion of methane-air mixtures: Validation and reduction. Combustion and Flame, 2022, 240, pp.111990. 10.1016/j.combustflame.2022.111990 . hal-03581400

\author{
HAL Id: hal-03581400 \\ https://hal.science/hal-03581400
}

Submitted on 20 Feb 2022

HAL is a multi-disciplinary open access archive for the deposit and dissemination of scientific research documents, whether they are published or not. The documents may come from teaching and research institutions in France or abroad, or from public or private research centers.
L'archive ouverte pluridisciplinaire HAL, est destinée au dépôt et à la diffusion de documents scientifiques de niveau recherche, publiés ou non, émanant des établissements d'enseignement et de recherche français ou étrangers, des laboratoires publics ou privés. 


\title{
Plasma assisted combustion of methane-air mixtures: Validation and reduction
}

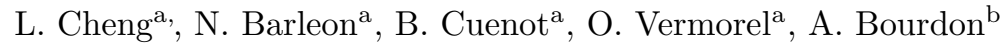 \\ ${ }^{a}$ CERFACS, 42 Avenue Gaspard Coriolis, 31057 Toulouse, Cedex 1, France \\ ${ }^{b}$ Laboratoire de Physique des Plasmas (LPP), CNRS, Sorbonne Université, Ecole Polytechnique, Institut Polytechnique de \\ Paris, 91120 Palaiseau, France
}

\begin{abstract}
For several years now plasma assisted combustion has been the subject of intense research due to stabilization effects a plasma can have on flames. Particularly, experiments have shown the promising impact of Nanosecond Repetitively Pulsed discharges on combustion while not exceeding an energy consumption of a few percent of the flame power. In this work, an incremental methodology with a step-by-step approach has been used to build a single plasma mechanism upon which combustion is added using the GRI 3.0 and Konnov v0.6. The methodology focuses on three key aspects of plasma assisted combustion: fast gas heating, slow gas heating and radical production. Selected experiments focusing on one or more of these aspects allow to validate the mechanism in large ranges of temperature $(300-1500 \mathrm{~K})$ and pressure $(0.1-1 \mathrm{bar})$ in air, methane-air and argon diluted mixtures using glow and spark discharges. These experiments include a plasma assisted ignition case on which the ignition delay time is well captured by the mechanism. Slow gas heating has been modeled using a vibrational relaxation model validated against a detailed vibrational description. Discussions on ambiguous rates for critical reactions of excited nitrogen quenching are made in the light of their impact on the results on the chosen experiments. Finally, the resulting 100-species GRI 3.0-based and 264-species Konnov v0.6-based plasma mechanisms are reduced to make them suitable for multi-dimensional simulations. The DRGEP reduction method, based on plasma experiments and canonical combustion cases, is applied allowing to reduce the number of species by a factor larger than two. For the GRI-3.0 plasma mechanism, the reduced mechanism contains 47 species and 429 reactions. Hence significant performance is gained, opening the way to multi-dimensional simulations of plasma assisted combustion.
\end{abstract}

Keywords: plasma assisted combustion, chemistry, discharges, reduction

\section{Introduction}

In the context of lean combustion for reduced environmental impact, plasma-assisted combustion is currently investigated by many groups to address stability and ignition issues.

Among the various types of discharges, Nanosecond Repetitively Pulsed (NRP) discharges have been experimentally shown to have a significant impact on flame stabilization [1] and ignition [2,3]. NRP discharges produce non-thermal plasmas and active radical species which lead to increased efficiency $[4,5]$.

Although their beneficial effect is well-known [6], the mechanisms at play in plasma-assisted combustion using NRP discharges are still not fully understood. In particular, the coupling between plasma physics and combustion thermochemistry is not yet clearly established. As this is difficult to address with experiments, numerical simulations may be used to analyze the flame-discharge interaction. Most of the studies including detailed kinetics are limited to 0D simulations $[7,8,9]$. One dimensional case $[10,11]$ or two-dimensional simulations $[12,13]$ of plasma-assisted methane combustion are usually limited to simplified chemistry. To

\footnotetext{
^ Declaration of interest: none

Email address: cheng@cerfacs.fr (L. Cheng)
}

Preprint accepted by Combustion and Flame 
avoid excessive computational cost of a detailed chemistry in a 3D configuration, a phenomenological model which mimic plasma discharge effects has been recently used in [14] allowing to model several hundred of discharges. A trade-off between detailed and phenomenological models is to use chemical reduction: by choosing suitable targets and cases, accuracy is preserved while keeping the computational cost reasonable. This method has already proven its worth in a combustion framework [15, 16] and is considered as an interesting basis for the reduction of plasma-combustion kinetic mechanism [17].

Contrary to thermal discharges, NRP discharges provide a chemical effect on top of the thermal effect due to the non-equilibrium electrons that allow to efficiently produce excited states of atoms and molecules through electron-neutral collisions. In air, electronically excited states contribute to fast gas heating by spontaneous dissociation or quenching of electronically excited nitrogen molecules as identified by Popov in [18]. Vibrationally excited states also play a role in gas heating allowing to store energy into the vibrational modes of nitrogen molecule which is further released through vibration-translation (VT) and vibrationvibration (VV) relaxations [19].

Having consistent and detailed chemistry is thus a critical basis for a good description of plasma-assisted combustion. Plasma air mechanisms have been derived and validated in [20, 7]. Despite good results from [20], a full description of the mechanism is lacking. Implementation of [7] does not give satisfactory results on one critical test case [21] because the mechanism was not validated at high temperature $(\simeq 1500 \mathrm{~K})$ and atmospheric pressure. Complete plasma air sets that are concatenated from different sources can also be found in $[22,23]$. However, the validity of these sets of reactions is not verified for plasma-assisted combustion application. An important review of plasma-assisted combustion chemistry has been done in [24]. While the most important processes and their effects are highlighted, it is not straightforward to derive a complete kinetic mechanism relying solely on [24]. In [8], a detailed plasma-assisted combustion mechanism has been used to study ignition with pre-calculated electron impact reaction rates. Although computationally efficient, this strategy limits the conditions on which the detailed mechanism is valid. Indeed, important changes in initial conditions such as mixture composition can drastically change electron impact reaction rates, thus requiring their recalculations. The self-consistent computation of these rates during simulations through an Electron Energy Distribution Function (EEDF) solver such as [25] is thus more appropriate to derive a versatile mechanism.

The present work introduces new detailed plasma-assisted combustion mechanisms that are valid for a wide range of temperatures $([300 \mathrm{~K}-1500 \mathrm{~K}])$ and pressures $([0.1$ bar -1.0 bar $])$. Critical reaction rates, such as those of nitrogen excited states quenching, are not unambiguously established in the literature. These uncertainties lead to noticeable differences in two major features of plasma discharge effects: fast gas heating and radical production. In [26], the reaction rate for the quenching of $\mathrm{N}_{2}(\mathrm{~B}, \mathrm{C})$ with $\mathrm{O}_{2}$ is said to be gas kinetics, meaning an underlying hard-sphere model for the cross-sections. On the other hand, experiments from [21] derived another rate for the quenching of $\mathrm{N}_{2}(\mathrm{C})$ with $\mathrm{O}_{2}$ from measurements which highlights a temperature dependence that is not captured by a hard-sphere model. The quenching of $\mathrm{N}_{2}(\mathrm{~B}, \mathrm{C}$, a) with $\mathrm{O}$ introduced in [26] for discharges with high dissociation degree is questionable as it was not brought to light in any experiment. Fast gas heating is a major component of any plasma-assisted combustion mechanism: in this work, the straightforward approach of considering the enthalpy change of a reaction for gas heating is compared with the fast gas heating model developed in [18].

The iterative process of construction of such a mechanism is highlighted in Section 3: after having built a plasma air mechanism, plasma methane reactions are added. Combustion mechanisms are finally applied on top of it with a specific merging procedure. Systematic validation of mechanisms against several experiments $[21,27,28,29]$, presented in Section 4, is performed after each upgrade in Section 5, thus validating different aspects of the chemistry: fast and slow gas heating as well as radical production. The fast gas heating model of [18] is tested and faced against the convential definition of heat release of reactions. Effects of uncertainties on the $\mathrm{N}_{2}{ }^{*}$ quenching rates by $\mathrm{O}_{2}$ and $\mathrm{O}$ are evaluated in terms of gas heating and radical production. The validation across a large range of temperature, composition and pressure prevents any overfitting of a mechanism to match a specific experiment.

As the mechanism is rather computationally expensive for dimensional simulations, a reduction step is mandatory. In [17], an extension of the DRGEP [15] reduction method was employed to reduce the mechanism of [30]. In this work, the original DRGEP method developed in ARCANE [16] is successfully 
employed to reduce the detailed mechanism in Section 6 without the need of any plasma specific procedure by choosing suitable reduction cases.

\section{Modeling plasma assisted combustion}

Zero-dimensional reactors have been chosen as first test cases to study plasma assisted combustion. The mass fractions $Y_{k}$ and the gas temperature $T_{g}$ are governed by:

$$
\begin{aligned}
m \frac{\mathrm{d} Y_{k}}{\mathrm{~d} t} & =V \dot{\omega}_{k} \\
m c_{v} \frac{\mathrm{d} T_{g}}{\mathrm{~d} t} & =-P \frac{\mathrm{d} V}{\mathrm{~d} t}+V \dot{\omega}_{T}+\dot{Q}
\end{aligned}
$$

where $m$ is the mass of the mixture, $t$ the time, $\omega_{k}$ the mass reaction rate of species $k, P$ the pressure, $V$ the volume, $c_{v}$ the mass heat capacity at constant volume, $\omega_{T}$ the heat release rate and $\dot{Q}$ is a power source term explicited in Section. 3.3.

In low temperature plasmas, the ionization degree, i.e. the proportion of charged species in the mixture, is rather low, reaching at most $10^{-4}-10^{-3}$. However, thanks to the strong electric field in plasma discharges, electrons are much more energetic than other heavy species. The resulting electron-neutral collisions can efficiently produce reactive species such as radicals or excited states, driving the electron distribution far from a Maxwellian one. It is thus important to know the electron distribution function $f_{e}\left(\mathbf{r}, \mathbf{v}_{e}, t\right)$, with $\mathbf{r}$ the position and $\mathbf{v}_{e}$ the electron velocity, which obeys the Boltzmann equation:

$$
\frac{\partial f_{e}}{\partial t}+\mathbf{v}_{e} \cdot \nabla f_{e}-\frac{e \mathbf{E}}{m_{e}} \cdot \nabla_{v} f_{e}=\left(\frac{\delta f_{e}}{\delta t}\right)_{c}
$$

where $\mathbf{E}$ is the electric field and $m_{e}$ the electron mass. $\nabla_{v}$ corresponds to gradient in velocity space. The collision term $\left(\delta f_{e} / \delta t\right)_{c}$ is computed from a complete set of cross sections containing mostly electron-neutral collisions.

Assuming a two-term expansion, the electron distribution function $f_{e}$ can be written as the product of the EEDF $F_{0}$ and the electron density $n_{e}[25]$. The Boltzmann equation Eq. (3) is then recast in terms of $F_{0}$ and solved. It is then used to compute the reaction rate $k_{j}$ associated to the cross-section $\sigma_{j}$ and the effective electron temperature $T_{e}$ by integrating over energy $\varepsilon[25]$ :

$$
\begin{aligned}
& k_{j}=\gamma \int_{0}^{\infty} \varepsilon \sigma_{j} F_{0} d \varepsilon \\
& T_{e}=\frac{2}{3} \int_{0}^{\infty} \varepsilon^{3 / 2} F_{0} d \varepsilon
\end{aligned}
$$

with $\gamma=\sqrt{\frac{2 e}{m_{e}}}$ a constant and $\varepsilon=(v / \gamma)^{2}$ the electron energy in electron-volt. In typical discharges, $T_{e}$ rises up to $5 \mathrm{eV}$.

As a consequence, in the mass reaction rate $\dot{\omega}_{k}$ and heat release rate $\dot{\omega}_{T}$ of Eqs. (1) and (2), two contributions may be distinguished: the set of EEDF reactions $\mathcal{B}$ (linked to an EEDF cross-section - superscript $b$ ) and the set of classical chemical reactions $\mathcal{C}$ (all the other ones - superscript $c$ ):

$$
\begin{aligned}
& \dot{\omega}_{k}=\dot{\omega}_{k}^{b}+\dot{\omega}_{k}^{c}=\sum_{j \in \mathcal{B}} \dot{\omega}_{k j}+\sum_{j \in \mathcal{C}} \dot{\omega}_{k j} \\
& \dot{\omega}_{T}=-\sum_{j \in \mathcal{B}} \dot{Q}_{j}\left(\Delta u_{j}-\varepsilon_{\mathrm{th}}^{j}\right)-\sum_{j \in \mathcal{C}} \dot{Q}_{j} \Delta u_{j}
\end{aligned}
$$


where $\varepsilon_{\text {th }}^{j}$ is the energy lost during process $j$ taken from cross-section datasets, $\Delta u_{j}=\sum_{k} \nu_{k j} u_{k}$ is the reaction energy change per mole with $u_{k}$ the internal energy of species $k . \dot{Q}_{j}$ is the molar production rate of reaction $j$ and is proportional to the reaction rate $k_{j}$. For the set of reactions $\mathcal{B}$, the reaction rate $k_{j}$ is given by Eq. (4) while for the set of reactions $\mathcal{C}$ an extension of Arrhenius law including electron temperature $T_{e}$ is employed:

$$
k_{j}=A_{j} T_{g}^{\beta_{j}} \exp \left(-\frac{E_{a}}{R T_{g}}\right) T_{e}^{\beta_{j}^{\prime}} \exp \left(-\frac{E_{a}^{\prime}}{R T_{e}}\right)
$$

In this work, the CANTERA code [31] has been used to solve Eqs. (1) and (2). An EEDF solver has been implemented in CANTERA, based on an open-source version of BOLSIG+ [25] named BOLOS, written by Alejandro Luque. Some features such as the energy grid adaptation of the open-source solver LOKI-B [32] have been introduced in our EEDF solver.

\section{Chemical mechanisms}

The plasma-assisted combustion mechanism is built in two steps. First, a chemical mechanism that describes the plasma dynamics is built based on the literature. Then, this mechanism is adapted to account for specific gas heating features of a plasma discharge. Finally, the plasma mechanism is merged with a combustion mechanism. In this work, two well-established schemes for methane-air combustion are tested: the GRI 3.0 [33] and the Konnov v0.6 [34].

\subsection{Plasma mechanism}

The cross sections for electron collisions with neutrals are taken from various datasets of the LXCat database (see Tab. 1) and associated reactions are included in the mechanism. Elastic cross-sections have been included for the (B, C, a) electronic states of $\mathrm{N}_{2}$, assumed to be the same as for the ground state $\mathrm{N}_{2}$. The electronically excited triplet states $N_{2}\left(B^{3} \Pi_{\mathrm{g}}\right)-\mathrm{N}_{2}\left(\mathrm{~B}^{\prime 3} \Sigma_{\mathrm{u}}^{-}\right)-\mathrm{N}_{2}\left(\mathrm{~W}^{3} \Delta_{\mathrm{u}}\right)$ and singlet states $\mathrm{N}_{2}\left(\mathrm{a}^{1} \Pi_{\mathrm{g}}\right)-$ $\mathrm{N}_{2}\left(\mathrm{a}^{\prime 1} \Sigma_{\mathrm{u}}^{-}\right)-\mathrm{N}_{2}\left(\mathrm{w}^{1} \Delta_{\mathrm{u}}\right)$ are lumped into the $\mathrm{N}_{2}\left(\mathrm{~B}^{3} \Pi_{\mathrm{g}}\right)$ and $\mathrm{N}_{2}\left(\mathrm{a}^{1} \Pi_{\mathrm{g}}\right)$ states respectively. To preserve the discharge energy transfer to the gas mixture, the difference of excitation energies is assumed to be converted into gas heating when produced by electron impact reactions. This procedure is illustrated in Reaction (R1) where the $\mathrm{N}_{2}\left(\mathrm{~W}^{3} \Delta_{\mathrm{u}}\right)$ state is lumped into $\mathrm{N}_{2}\left(\mathrm{~B}^{3} \Pi_{\mathrm{g}}\right)$. Consequently, the difference of energies between these two states must be accounted for into the heat release of the reaction.

$$
\mathrm{e}^{-}+\mathrm{N}_{2} \longrightarrow \mathrm{e}^{-}+\mathrm{N}_{2}\left(\mathrm{~W}^{3} \Delta_{\mathrm{u}}\right) \longrightarrow \mathrm{e}^{-}+\mathrm{N}_{2}\left(\mathrm{~B}^{3} \Pi_{\mathrm{g}}\right)+0.81 \mathrm{eV}
$$

Electron impact reactions need to be supplemented with electron-ion and heavy species reactions to form a complete kinetic mechanism for plasma discharge. Two references ([22, Chap. 7-10], [18]) have been chosen to construct the plasma mechanism with which the combustion mechanism will be merged. As argon is often used as diluent in plasma assisted combustion studies [29], a quite simple plasma chemistry for Ar has been taken from [35] to handle mixture dilution with this noble gas. The detailed plasma mechanism finally contains 71 species and 680 reactions. A complete description of the plasma mechanism can be found in the supplementary materials $\mathrm{S} 2$.

\begin{tabular}{|c|c|}
\hline Colliding partners & $\sigma$ \\
\hline $\mathrm{N}_{2}, \mathrm{~N}_{2}\left(\mathrm{~A}^{3} \Sigma_{\mathrm{u}}^{+}\right), \mathrm{N}_{2}\left(\mathrm{~B}^{3} \Pi_{\mathrm{g}}\right), \mathrm{N}_{2}\left(\mathrm{C}^{3} \Pi_{\mathrm{u}}\right), \mathrm{N}_{2}\left(\mathrm{a}^{1} \Pi_{\mathrm{g}}\right), \mathrm{O}_{2}, \mathrm{Ar}$ & Phelps [36] \\
$\mathrm{O}_{2}\left(\mathrm{a}^{1} \Delta_{\mathrm{g}}\right), \mathrm{O}_{2}\left(\mathrm{~b}_{1} \Sigma_{\mathrm{g}}^{+}\right)$ & Triniti [37] \\
$\mathrm{CH}_{4}, \mathrm{NO}, \mathrm{N}_{2} \mathrm{O}$ & Hayashi [38] \\
$\mathrm{O}\left({ }^{3} \mathrm{P},{ }^{1} \mathrm{D},{ }^{1} \mathrm{~S}\right), \mathrm{N}\left({ }^{4} \mathrm{~S},{ }^{2} \mathrm{D}\right)$ & MST-Lisbon [39] \\
$\mathrm{O}_{3}$ & Morgan [40] \\
$\mathrm{N}_{2}(\mathrm{v})$ & {$[36,39,41]$} \\
\hline
\end{tabular}

Table 1: Electron impact cross-sections used in this work. 


\subsection{Fast gas heating modeling}

Usually the enthalpy change of a reaction is associated with heat release leading to an increase or decrease of the gas temperature. Table 2 illustrates the different behaviors of EEDF reactions (set $\mathcal{B}$ ) with two examples. In the first process of Tab. 2, the whole energy lost by the electron is transferred to the electronic state $\mathrm{N}_{2}(\mathrm{~A})$. Consequently, there is no heat release in this reaction. However, some electron impact processes can release heat. This is the case of the second process of Tab. 2 in which the electron looses more energy than necessary to dissociate $\mathrm{O}_{2}$. This excess of energy is associated to gas heating in the kinetic modeling.

\begin{tabular}{|c|c|c|c|c|}
\hline$\#$ & Process & $\varepsilon_{\text {th }}[\mathrm{eV}]$ & $\Delta u[\mathrm{eV}]$ & $\Delta u-\varepsilon_{\text {th }}[\mathrm{eV}]$ \\
\hline 1 & $\mathrm{e}^{-}(\varepsilon)+\mathrm{N}_{2} \longrightarrow \mathrm{e}^{-}\left(\varepsilon-\varepsilon_{\text {th }}\right)+\mathrm{N}_{2}(\mathrm{~A})$ & 6.17 & 6.17 & 0 \\
\hline 2 & $\mathrm{e}^{-}(\varepsilon)+\mathrm{O}_{2} \longrightarrow \mathrm{e}^{-}\left(\varepsilon-\varepsilon_{\text {th }}\right)+2 \mathrm{O}$ & 6.0 & 5.16 & -0.84 \\
\hline
\end{tabular}

Table 2: Example of electron impact reactions.

For the other reactions $($ set $\mathcal{C})$, part of the products energy is stored into rotational and vibrational modes as suggested by Popov $[18,42]$ and references therein. To account for this phenomenon, the heat release rate of some reactions is forced to the Fast Gas Heating (FGH, Model 1) values listed in Tab. 3 according to the work of $[18,42]$. In this table, FGH corresponds to the forced energy release per molecule (either observed experimentally or computed using the methodology of [18]) and HRR (Model 2) refers to the use of the conventional definition of Heat Release of Reaction using the formation enthalpy of the reactants and products. At the end, energy conservation is ensured through a vibrational energy residual $\varepsilon_{\text {vib }}$ in the products following Eq. (9), discussed in more details in Section 3.3.

$$
\varepsilon_{\mathrm{vib}}=\mathrm{HRR}-\mathrm{FGH}
$$

\begin{tabular}{|c|c|c|c|c|}
\hline \multirow[t]{2}{*}{ Num } & \multirow[t]{2}{*}{ Reaction } & \multicolumn{2}{|c|}{ Model 1} & Model 2 \\
\hline & & FGH $[\mathrm{eV}]$ & Ref & $\mathrm{HRR}[\mathrm{eV}]$ \\
\hline (A1) & $\mathrm{e}^{-}+\mathrm{N}_{4}+\longrightarrow \mathrm{N}_{2}(\mathrm{v})+\mathrm{N}_{2}(\mathrm{C})$ & 0 & [43] & 3.4 \\
\hline (A2) & $\mathrm{N}_{2}(\mathrm{~A})+\mathrm{O}_{2} \longrightarrow \mathrm{N}_{2}(\mathrm{v})+\mathrm{O}_{2}\left(\mathrm{~b}_{1}\right)$ & 0 & [18] & 4.53 \\
\hline (A3) & $\mathrm{N}_{2}(\mathrm{~A})+\mathrm{N}_{2}(\mathrm{~A}) \longrightarrow \mathrm{N}_{2}(\mathrm{v})+\mathrm{N}_{2}(\mathrm{C})$ & 0.4 & [18] & 1.3 \\
\hline (A4) & $\mathrm{N}_{2}(\mathrm{~A})+\mathrm{N}_{2}(\mathrm{~A}) \longrightarrow \mathrm{N}_{2}(\mathrm{v})+\mathrm{N}_{2}(\mathrm{~B})$ & 3.5 & [18] & 4.99 \\
\hline (A5) & $\mathrm{N}_{2}(\mathrm{~B})+\mathrm{O}_{2} \longrightarrow \mathrm{N}_{2}(\mathrm{v})+2 \mathrm{O}$ & 1.1 & {$[18$, Eq. 6$]$} & 2.19 \\
\hline (A6) & $\mathrm{N}_{2}(\mathrm{~B})+\mathrm{N}_{2} \longrightarrow \mathrm{N}_{2}(\mathrm{~A})+\mathrm{N}_{2}(\mathrm{v})$ & 0 & [43] & 1.18 \\
\hline (A7) & $\mathrm{N}_{2}(\mathrm{a})+\mathrm{N}_{2} \longrightarrow \mathrm{N}_{2}(\mathrm{~B})+\mathrm{N}_{2}(\mathrm{v})$ & 0 & [43] & 1.05 \\
\hline (A8) & $\mathrm{N}_{2}(\mathrm{C})+\mathrm{O}_{2} \longrightarrow \mathrm{N}_{2}(\mathrm{v})+\mathrm{O}+\mathrm{O}$ & 5.55 & {$[18$, Eq. 6$]$} & 5.87 \\
\hline (A9) & $\mathrm{N}_{2}(\mathrm{C})+\mathrm{O}_{2} \longrightarrow \mathrm{N}_{2}(\mathrm{v})+\mathrm{O}+\mathrm{O}\left({ }^{1} \mathrm{D}\right)$ & 3.59 & {$[18$, Eq. 6$]$} & 3.99 \\
\hline (A10) & $\mathrm{N}_{2}(\mathrm{C})+\mathrm{O}_{2} \longrightarrow \mathrm{N}_{2}(\mathrm{v})+\mathrm{O}+\mathrm{O}\left({ }^{1} \mathrm{~S}\right)$ & 1.37 & {$[18$, Eq. 6$]$} & 1.68 \\
\hline (A11) & $\mathrm{N}_{2}(\mathrm{C})+\mathrm{N}_{2} \longrightarrow \mathrm{N}_{2}(\mathrm{~B})+\mathrm{N}_{2}(\mathrm{v})$ & 0 & {$[18,43]$} & 3.68 \\
\hline (A12) & $\mathrm{O}\left({ }^{1} \mathrm{D}\right)+\mathrm{O}_{2} \longrightarrow \mathrm{O}+\mathrm{O}_{2}(\mathrm{v})$ & 0 & [18] & 1.97 \\
\hline (A13) & $\mathrm{O}\left({ }^{1} \mathrm{D}\right)+\mathrm{O}_{2} \longrightarrow \mathrm{O}+\mathrm{O}_{2}\left(\mathrm{a}_{1}, \mathrm{v}\right)$ & 0 & {$[18]$} & 0.99 \\
\hline (A14) & $\mathrm{O}\left({ }^{1} \mathrm{D}\right)+\mathrm{O}_{2} \longrightarrow \mathrm{O}+\mathrm{O}_{2}\left(\mathrm{~b}_{1}, \mathrm{v}\right)$ & 0 & {$[18]$} & 0.34 \\
\hline (A15) & $\mathrm{O}\left({ }^{1} \mathrm{D}\right)+\mathrm{N}_{2} \longrightarrow \mathrm{O}+\mathrm{N}_{2}(\mathrm{v})$ & 1.38 & [18] & 1.97 \\
\hline
\end{tabular}

Table 3: Fast Gas Heating (FGH) and conventional Heat Release of Reaction (HRR) for reactions for which they differ.

Among these reactions, it is well known that the dissociative quenching of electronically excited states $\mathrm{N}_{2}{ }^{*}$ with $\mathrm{O}_{2}$ (Reaction (R2)) largely contributes to the fast gas heating and the production of atomic oxygen.

$$
\mathrm{N}_{2}{ }^{*}+\mathrm{O}_{2} \longrightarrow \mathrm{N}_{2}+2 \mathrm{O}
$$

In particular, $\mathrm{N}_{2}\left(\mathrm{~B}^{3} \Pi_{\mathrm{g}}\right), \mathrm{N}_{2}\left(\mathrm{a}^{1} \Pi_{\mathrm{g}}\right)$ and $\mathrm{N}_{2}\left(\mathrm{C}^{3} \Pi_{\mathrm{u}}\right)$ dissociate $\mathrm{O}_{2}$ with a high reaction rate while $\mathrm{N}_{2}\left(\mathrm{~A}^{3} \Sigma_{\mathrm{u}}^{+}\right)$dissociates $\mathrm{O}_{2}$ at a rate two orders of magnitude lower at room temperature [44]. In [7], the rate of reaction (R2) was taken constant for $\mathrm{N}_{2}{ }^{*}=\mathrm{N}_{2}\left(\mathrm{~B}^{3} \Pi_{\mathrm{g}}\right), \mathrm{N}_{2}\left(\mathrm{a}^{1} \Pi_{\mathrm{g}}\right), \mathrm{N}_{2}\left(\mathrm{C}^{3} \Pi_{\mathrm{u}}\right)$ at a value of 
$3 \times 10^{-10} \mathrm{~cm}^{3} \mathrm{~s}^{-1}$. Similar reaction rates are used in [44] for $\mathrm{N}_{2}\left(\mathrm{~B}^{3} \Pi_{\mathrm{g}}\right)$ and $\mathrm{N}_{2}\left(\mathrm{C}^{3} \Pi_{\mathrm{u}}\right)$. While global agreement on the dissociative quenching rates for $N_{2}\left(A^{3} \Sigma_{u}^{+}\right), N_{2}\left(B^{3} \Pi_{g}\right)$ and $N_{2}\left(C^{3} \Pi_{u}\right)$ is reached in the literature, the case of $\mathrm{N}_{2}\left(\mathrm{a}^{1} \Pi_{\mathrm{g}}\right)$ is ambiguous. In most of the plasma-assisted combustion studies, the rate for $\mathrm{N}_{2}\left(\mathrm{a}^{1} \Pi_{\mathrm{g}}\right)$ is one order of magnitude smaller than $\mathrm{N}_{2}\left(\mathrm{~B}^{3} \Pi_{\mathrm{g}}\right)$ and $\mathrm{N}_{2}\left(\mathrm{C}^{3} \Pi_{\mathrm{u}}\right)$ states. For the $\mathrm{N}_{2}\left(\mathrm{a}^{1} \Pi_{\mathrm{g}}\right)$ state, the rate coefficient used in [44] $\left(2.8 \times 10^{-11} \mathrm{~cm}^{3} \mathrm{~s}^{-1}\right)$ was taken from [45] and corresponds to the quenching of the $\mathrm{N}_{2}\left(\mathrm{a}^{1} \Sigma_{\mathrm{u}}^{-}\right)$state. In [46], the rate coefficient of the quenching of $\mathrm{N}_{2}\left(\mathrm{a}^{1} \Pi_{\mathrm{g}}\right)$ with $\mathrm{O}_{2}$ has been measured experimentally and was found high at $4.3 \times 10^{-10} \mathrm{~cm}^{3} \mathrm{~s}^{-1}$. The ratio of singlet excited states $\mathrm{N}_{2}\left(\mathrm{a}^{1} \Pi_{\mathrm{g}}\right)$ production by electron impact reactions in air calculated with BOLSIG+ is depicted in Fig. 1, showing that $\mathrm{N}_{2}\left(\mathrm{a}^{1} \Pi_{\mathrm{g}}\right)$ is dominant among $\mathrm{N}_{2}\left(\mathrm{a}^{1} \Sigma_{\mathrm{u}}^{-}, \mathrm{a}^{1} \Pi_{\mathrm{g}}, \mathrm{w}^{1} \Delta_{\mathrm{u}}\right)$ for electric fields higher than $100 \mathrm{Td}$ with more than $50 \%$ of the overall production of singlet states. The state $\mathrm{N}_{2}\left(\mathrm{a}^{\prime 1} \Sigma_{\mathrm{u}}^{-}\right)$only represents about $20 \%$ of the singlet states produced by the discharge.

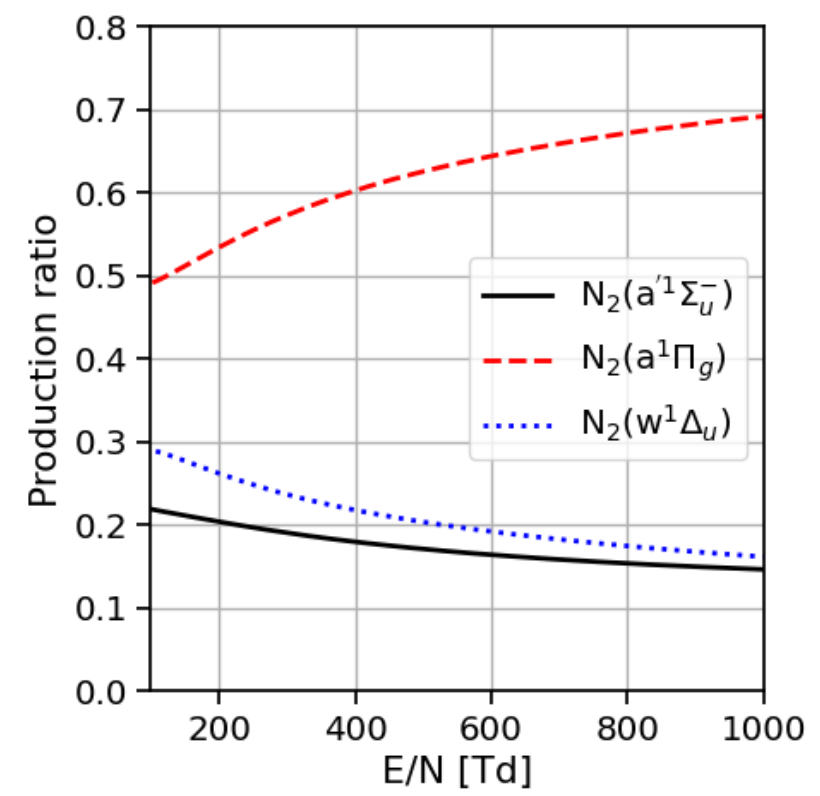

Figure 1: Ratio of production rates of singlet excited states of $\mathrm{N}_{2}$ using BOLSIG+ [25].

The timescale of (R2) for $\mathrm{N}_{2}\left(\mathrm{a}^{1} \Pi_{\mathrm{g}}\right)$ is of the order of $3 \mathrm{~ns}$ in air at $T=1500 \mathrm{~K}$ and atmospheric pressure assuming $X_{\mathrm{O}_{2}}=0.15$. According to [22], the $\mathrm{N}_{2}\left(\mathrm{a}^{1} \Pi_{\mathrm{g}}\right) \rightarrow \mathrm{N}_{2}\left(\mathrm{a}^{1} \Sigma_{\mathrm{u}}^{-}\right)$optical transition occurs on the millisecond timescale, which is much higher than the timescale of $(\mathrm{R} 2)$. The $\mathrm{N}_{2}\left(\mathrm{a}^{1} \Pi_{\mathrm{g}}\right)$ collisional quenching timescale of reaction (R3) is also higher by one order of magnitude (20 ns) compared with the $\mathrm{O}_{2}$ dissociative quenching timescale. Thus, during the very first nanoseconds following the pulse, it can be concluded that $\mathrm{N}_{2}\left(\mathrm{a}^{\prime 1} \Sigma_{\mathrm{u}}^{-}, \mathrm{a}^{1} \Pi_{\mathrm{g}}, \mathrm{w}^{1} \Delta_{\mathrm{u}}\right)$ is mainly composed of $\mathrm{N}_{2}\left(\mathrm{a}^{1} \Pi_{\mathrm{g}}\right)$.

$$
\mathrm{N}_{2}\left(\mathrm{a}^{1} \Pi_{\mathrm{g}}\right)+\mathrm{M} \longrightarrow \mathrm{N}_{2}\left(\mathrm{a}^{\prime 1} \Sigma_{\mathrm{u}}^{-}\right)+\mathrm{M}, \quad k=9 \times 10^{-12} \mathrm{~cm}^{3} \mathrm{~s}^{-1}
$$

Finally, three different models for gas heating are tested, and referred as follows. Model 1 considers the forced energy release of the reaction in Tab. 3, Model 2 refers to the use of the conventional HRR and Model 3 is based upon Model 1 with the rate from [46] for the dissociative quenching of $\mathrm{O}_{2}$ by $\mathrm{N}_{2}\left(\mathrm{a}^{1} \Pi_{\mathrm{g}}\right)$.

\subsection{Slow gas heating modeling}

The fast gas heating produced by a plasma discharge is followed by a slow gas heating corresponding to the relaxation of vibrational states. For the discharges considered in this work $(E / N \geq 10 \mathrm{Td})$, an overwhelming 
majority of this energy is stored into vibrational modes of $\mathrm{N}_{2}$ [1]. Thus, a detailed or simplified modeling of $\mathrm{N}_{2}(\mathrm{v})$ is included in the kinetic mechanism and a simplified model for $\mathrm{O}_{2}(\mathrm{v})$ is always used. In the detailed model VIB. 1, the electron vibrational excitation cross sections are taken from [39] and [36] for $\mathrm{N}_{2}(\mathrm{v}=1-8)$ and from [41] for $\mathrm{N}_{2}(\mathrm{v}=9-17)$. The main relaxation processes are vibrational-translational $(\mathrm{VT}) \mathrm{N}_{2}-\mathrm{O}$ and vibrational-vibrational ( $\mathrm{VV}) \mathrm{N}_{2}-\mathrm{N}_{2}$ reactions and as a first approximation only those processes have been accounted for in the detailed model:

$$
\begin{aligned}
& \mathrm{N}_{2}(v)+\mathrm{O} \longleftrightarrow \mathrm{N}_{2}(v-1)+\mathrm{O} \\
& \mathrm{N}_{2}(v)+\mathrm{N}_{2}(w-1) \longleftrightarrow \mathrm{N}_{2}(v-1)+\mathrm{N}_{2}(w)
\end{aligned}
$$

The vibrational energy of level $\mathrm{v}, E_{v}$, accounts for anharmonicity effects, using a Morse potential energy expression:

$$
\frac{E_{v}}{h c}=\omega_{e}\left(v+\frac{1}{2}\right)-\omega_{e} x_{e}\left(v+\frac{1}{2}\right)^{2}
$$

where $h$ is the Planck constant, c the speed of light in vaccum, $\omega_{e}$ the characteristic vibrational pulsation and $\omega_{e} x_{e}$ the anharmonicity. $\omega_{e}$ and $\omega_{e} x_{e}$ are given in units of wavelength and can be found in [22]. The base rate and scaling for both VV and VT relaxations are taken from [19]. The resulting mechanism contains 116 species (71 species of the plasma mechanism developed above plus 45 vibrational states $\mathrm{N}_{2}(\mathrm{v}=1,45)$ ) and 1916 reactions.

The modeling of the vibration kinetics of species $k$ can be simplified by considering the mean nonequilibrium vibrational energy $e_{\mathrm{vib}}^{k}$. The time evolution of $e_{\mathrm{vib}}^{k}$ and its interaction with the gas temperature are given by:

$$
\begin{aligned}
\frac{d e_{\mathrm{vib}}^{k}}{d t} & =\dot{E}_{\mathrm{vib}}^{k}-\dot{R}_{\mathrm{VT}}^{k} \\
m c_{v} \frac{\mathrm{d} T_{g}}{\mathrm{~d} t} & =-P \frac{\mathrm{d} V}{\mathrm{~d} t}+V \dot{\omega}_{T}+\sum_{k} \dot{R}_{\mathrm{VT}}^{k}
\end{aligned}
$$

In Eq. (11), $\dot{E}_{\mathrm{vib}}^{k}$ corresponds to vibrational excitation of species $k$ produced by the discharge. Reactions such as (A6) and (A7) do not produce any heating and instead the energy is deposited as molecular vibration in $\dot{E}_{\mathrm{vib}}^{\mathrm{N} 2}$. The sink term $\dot{R}_{\mathrm{VT}}^{k}$ corresponds to the vibrational-translational (VT) relaxation from species $k$ :

$$
\dot{R}_{\mathrm{VT}}^{k}=\frac{e_{\mathrm{vib}}^{k}}{\tau_{\mathrm{VT}}^{k}} \quad \tau_{\mathrm{VT}}^{k}=\left(\sum_{p} 1 / \tau_{\mathrm{VT}}^{p k}\right)
$$

where $\theta_{\nu}^{k}$ represents the characteristic vibrational temperature. Each relaxing species $k$ has several colliding partners (denoted by $p$ above). Note that the power source term $\dot{Q}$ of Eq. (2) has been expanded as $\dot{Q}=\sum_{k} \dot{R}_{\mathrm{VT}}^{k}$.

In the simplified model VIB. 2, the mean vibrational energy of $k=\mathrm{N}_{2}$ is considered with the colliding partners $p=\mathrm{O}, \mathrm{N}_{2}$ and the relaxation times $\tau_{\mathrm{VT}}^{p k}$ are taken from [47].

In both models VIB. 1 and VIB. 2, the relaxation of the vibrational energy of $\mathrm{O}_{2}$ is modeled using the simplified approach with the colliding partners $p=\mathrm{O}, \mathrm{N}_{2}, \mathrm{O}_{2}$ and relaxation times taken from [1]. Note that $\mathrm{O}_{2}\left(\mathrm{a}_{1}, v\right)$ and $\mathrm{O}_{2}\left(\mathrm{~b}_{1}, v\right)$ produced respectively by reactions (A14) and (A15) in Tab. 3 are modeled like $\mathrm{O}_{2}(\mathrm{v})$.

Using Model 1 (FGH) for reactions listed in Tab. 3 introduces reactions which produce vibrational species at an unknown distribution. It is thus impossible to include them in a detailed model of vibration and the 
corresponding vibrational energy residual is relaxed using Eq. (13), i.e., following model VIB. 2.

\subsection{Combustion mechanisms and merging with plasma mechanism}

To compute plasma-assisted combustion, methane is incorporated to the previous plasma air mechanism. First, plasma reactions involving methane are added to the mechanism. The most important ones are listed in Tab. 4 along with their references. Full description of the plasma methane kinetics can be found in the supplementary materials S2. Methane is able to create $\mathrm{H}$ radicals and is another possible partner for electronically excited nitrogen and oxygen.

\begin{tabular}{|c|c|c|}
\hline Reaction & $k_{f}\left[\mathrm{~cm}^{3} \mathrm{~s}^{-1}\right]$ & Ref. \\
\hline \multicolumn{3}{|c|}{ Electron-impact reactions } \\
\hline $\begin{array}{c}\mathrm{e}^{-}+\mathrm{CH}_{4} \longrightarrow \mathrm{e}^{-}+\mathrm{CH}_{3}+\mathrm{H} \\
\mathrm{e}^{-}+\mathrm{CH}_{4} \longrightarrow 2 \mathrm{e}^{-}+\mathrm{CH}_{4}+\end{array}$ & $\begin{array}{l}\sigma \\
\sigma\end{array}$ & $\begin{array}{l}{[48]} \\
{[48]}\end{array}$ \\
\hline \multicolumn{3}{|c|}{ Electron-ion recombination } \\
\hline $\begin{array}{c}\mathrm{e}^{-}+\mathrm{CH}_{4}^{+} \longrightarrow \mathrm{CH}_{3}+\mathrm{H} \\
\mathrm{e}^{-}+\mathrm{CH}_{4}+\longrightarrow \mathrm{CH}_{2}+2 \mathrm{H} \\
\mathrm{e}^{-}+\mathrm{CH}_{4}^{+} \longrightarrow \mathrm{CH}+\mathrm{H}_{2}+\mathrm{H}\end{array}$ & $\begin{array}{l}1.18 \times 10^{-8}\left(300 / T_{g}\right)^{0.5} \\
2.42 \times 10^{-8}\left(300 / T_{g}\right)^{0.5} \\
1.41 \times 10^{-8}\left(300 / T_{g}\right)^{0.5}\end{array}$ & $\begin{array}{l}{[49]} \\
{[49]} \\
{[49]}\end{array}$ \\
\hline \multicolumn{3}{|c|}{ Quenching of excited states } \\
\hline $\begin{array}{c}\mathrm{N}_{2}(\mathrm{~A})+\mathrm{CH}_{4} \longrightarrow \mathrm{N}_{2}+\mathrm{CH}_{3}+\mathrm{H} \\
\mathrm{N}_{2}(\mathrm{~B})+\mathrm{CH}_{4} \longrightarrow \mathrm{N}_{2}+\mathrm{CH}_{3}+\mathrm{H} \\
\mathrm{N}_{2}(\mathrm{C})+\mathrm{CH}_{4} \longrightarrow \mathrm{N}_{2}+\mathrm{CH}_{3}+\mathrm{H} \\
\mathrm{N}_{2}(\mathrm{a})+\mathrm{CH}_{4} \longrightarrow \mathrm{N}_{2}+\mathrm{CH}_{3}+\mathrm{H} \\
\mathrm{O}\left({ }^{1} \mathrm{D}\right)+\mathrm{CH}_{4} \longrightarrow \mathrm{CH}_{3}+\mathrm{OH} \\
\mathrm{O}\left({ }^{1} \mathrm{D}\right)+\mathrm{CH}_{4} \longrightarrow \mathrm{CH}_{3} \mathrm{O}+\mathrm{H}\end{array}$ & $\begin{array}{l}3.3 \times 10^{-15} \\
3 \times 10^{-10} \\
5 \times 10^{-10} \\
3 \times 10^{-10} \\
1.89 \times 10^{-10} \\
3.1 \times 10^{-11} \\
\end{array}$ & $\begin{array}{l}{[28]} \\
{[28]} \\
{[28]} \\
{[28]} \\
{[50]} \\
{[50]}\end{array}$ \\
\hline
\end{tabular}

Table 4: Major plasma reactions of $\mathrm{CH}_{4}$ containing mixture.

Combustion reactions now need to be added to the mechanism. Two combustion mechanisms are considered here to illustrate the merging mechanisms with chemistries of increasing complexity: the GRI-3.0 [33] mechanism (53 species, 325 reactions) and the Konnov [34] mechanism (201 species, 2300 reactions). Two global quantities of these mechanisms, namely the ignition delay time and the flame speed $S_{L}$, are given in Fig. 2. Auto-ignition is computed for stoichiometric mixture by varying initial temperature and flame speed is computed with a fresh gas temperature and pressure of $300 \mathrm{~K}$ and 1 atmosphere by varying the equivalence ratio. Regarding auto-ignition times in Fig. 2a, both mechanisms are in agreement when dealing with standard conditions. However, the addition of a small amount of atomic oxygen $\Delta Y_{\mathrm{O}}=1 \times 10^{-3}$ to mimic a plasma chemical effect reveals a noticeable difference between the two mechanisms. For both mechanisms, the addition of atomic oxygen reduces the ignition delay time but this effect is much stronger for the GRI-3.0 mechanism. Concerning flame speeds shown in Fig. 2b, a difference of about $10 \%$ is observed between the two mechanisms in the lean-to-stoichiometric region for standard conditions. The addition of atomic oxygen leads to a slightly higher flame speed in the stochiometric and stochiometric-rich regions for the GRI-3.0 and Konnov mechanisms respectively. Overall these preliminary results show that the two mechanisms behave similarly in standard conditions but their response to plasma conditions can be quite different. The procedure for merging the plasma and combustion mechanisms can now be detailed.

As the methane-air plasma mechanism was developed independently from the combustion mechanisms, some reactions are redundant. For the GRI 3.0 approximately 40 reactions already exist in the plasma mechanism while for the Konnov mechanism this number is close to 100. While some of these reactions use the same rate constants, most do not and a choice must be made.

\subsubsection{GRI 3.0}

In the case of GRI 3.0 mechanism, choosing the rate constants from one or the other mechanism has negligible effects on the plasma cases studies in this paper (see Section 4). Thus to be safe the rates of GRI 3.0 are kept as they were optimized for combustion applications. 


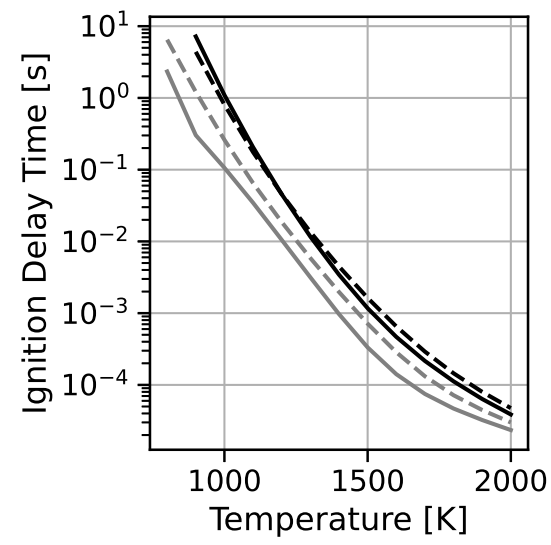

(a) Auto-ignition at $\phi=1$

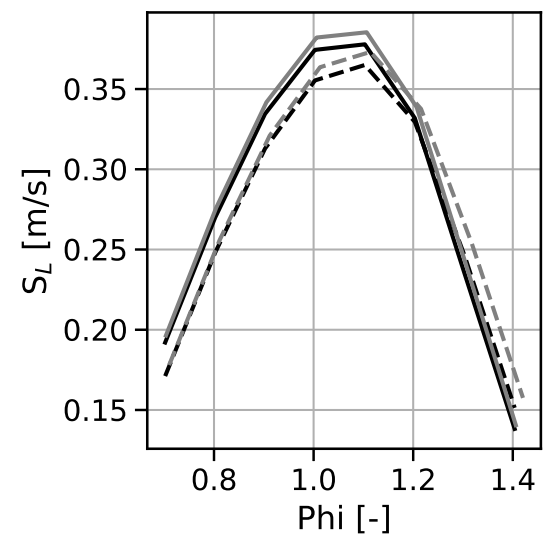

(b) Flame speed at $T_{0}=300 \mathrm{~K}, P_{0}=1 \mathrm{~atm}$

Figure 2: Comparison of the GRI-3.0 (solid lines) and Konnov (dashed lines) at normal composition (black) and with small atomic oxygen addition $\Delta Y_{\mathrm{O}}=1 \times 10^{-3}$ (gray) to mimic plasma discharge.

\subsubsection{Konnov v0.6}

As for the GRI 3.0, the rates of reactions involving atoms and molecules in their ground states can be taken from either mechanism without significant change in the cases of Section 4 . However the Konnov mechanism [34] contains some excited species as detailed in [51]: $\mathrm{O}\left({ }^{1} \mathrm{D}\right), \mathrm{O}_{2}(\Delta)$ and $\mathrm{OH}(\Sigma)$ denoted "OX", "O2X" and "OHX" respectively. The reactions involving these species are much more important than those with ground state species as they contain part of the discharge energy and need to be treated carefully. Some reaction rates have been modified from the original Konnov mechanism. Due to the merging of the singlet states of $\mathrm{O}_{2}$ in [34], the quenching of $\mathrm{O}\left({ }^{1} \mathrm{D}\right)$ by $\mathrm{O}_{2}$ is described in the original Konnov mechanism by:

$$
\mathrm{O}\left({ }^{1} \mathrm{D}\right)+\mathrm{O}_{2} \longrightarrow \mathrm{O}+\mathrm{O}_{2}\left(\mathrm{a}_{1}\right) \quad k=2.64 \times 10^{-11} \exp \left(139 / R T_{g}\right)
$$

As our chemistry considers two distinct species $\mathrm{O}_{2}\left(\mathrm{a}_{1}\right)$ and $\mathrm{O}_{2}\left(\mathrm{~b}_{1}\right)$, the rate coefficients of $\mathrm{O}\left({ }^{1} \mathrm{D}\right)$ quenching by $\mathrm{O}_{2}$ are described more precisely as in [22]:

$$
\begin{array}{lr}
\mathrm{O}\left({ }^{1} \mathrm{D}\right)+\mathrm{O}_{2} \longrightarrow \mathrm{O}+\mathrm{O}_{2} & k=6.4 \times 10^{-12} \exp \left(133 / R T_{g}\right) \mathrm{cm}^{3} \mathrm{~s}^{-1} \\
\mathrm{O}\left({ }^{1} \mathrm{D}\right)+\mathrm{O}_{2} \longrightarrow \mathrm{O}+\mathrm{O}_{2}\left(\mathrm{a}_{1}\right) & k=1 \times 10^{-12} \mathrm{~cm}^{3} \mathrm{~s}^{-1} \\
\mathrm{O}\left({ }^{1} \mathrm{D}\right)+\mathrm{O}_{2} \longrightarrow \mathrm{O}+\mathrm{O}_{2}\left(\mathrm{~b}_{1}\right) & k=2.6 \times 10^{-11} \exp \left(133 / R T_{g}\right) \mathrm{cm}^{3} \mathrm{~s}^{-1}
\end{array}
$$

The reaction rate used for reaction (R6) actually corresponds to that of reaction (R9). The underlying assumption is that the $\mathrm{O}_{2}\left(\mathrm{~b}_{1}\right)$ formed in reaction (R9) is directly quenched to form $\mathrm{O}_{2}\left(\mathrm{a}_{1}\right)$. This assumption is relaxed in the merging procedure as reaction (R6) is replaced by reactions (R7), (R8) and (R9).

Modifications have also been made to ensure correct repartition of the discharge energy: the heat release rate of some reactions was split into a fast gas heating and a slow gas heating following Eq. (9) based on [18]. Hence the three quenching reactions above are supposed to produce only vibrational energy. Likewise the quenching of reaction (R10) is described as in [18] with $30 \%$ of energy going into FGH and $70 \%$ into vibration. A summary of the modifications made on energy repartition and reaction rates for the merging with the Konnov mechanism is summarized in Tab. 5. 


$$
\mathrm{O}\left({ }^{1} \mathrm{D}\right)+\mathrm{N}_{2} \longrightarrow \mathrm{O}+\mathrm{N}_{2}(\mathrm{v})
$$

\begin{tabular}{|c|c|c|c|}
\hline Reaction & FGH $[\%]$ & Vibration $[\%]$ & $k_{f}\left[\mathrm{~cm}^{3} \mathrm{~s}^{-1}\right]$ \\
\hline $\mathrm{O}\left({ }^{1} \mathrm{D}\right)+\mathrm{O}_{2} \longrightarrow \mathrm{O}+\mathrm{O}_{2}(\mathrm{v})$ & 0 & 100 & $6.4 \times 10^{-12} \exp \left(67 / T_{g}\right)$ \\
$\mathrm{O}\left({ }^{1} \mathrm{D}\right)+\mathrm{O}_{2} \longrightarrow \mathrm{O}+\mathrm{O}_{2}(\mathrm{a}, \mathrm{v})$ & 0 & 100 & $10^{-12}$ \\
$\mathrm{O}\left({ }^{1} \mathrm{D}\right)+\mathrm{O}_{2} \longrightarrow \mathrm{O}+\mathrm{O}_{2}\left(\mathrm{~b}_{1}, \mathrm{v}\right)$ & 0 & 100 & $2.6 \times 10^{-11} \exp \left(67 / T_{g}\right)$ \\
$\mathrm{O}\left({ }^{1} \mathrm{D}\right)+\mathrm{N}_{2} \longrightarrow \mathrm{O}+\mathrm{N}_{2}(\mathrm{v})$ & 30 & 70 & $7.6 \times 10^{-11}$ \\
\hline
\end{tabular}

Table 5: Modified reactions in the Konnov mechanism according to our plasma mechanism. FGH and vibrational excitation are given in term of percentage of the energy change of reaction.

\section{Test cases}

\subsection{Cases overview}

Four experiments of NRP discharges taken from the literature are used to validate the models and chemistries described in Section 3. Their major characteristics are summarized in Tab. 6. These discharges correspond to typical electrode configurations depicted in Fig. 3 and cover either the glow [52] or spark [53] regimes of NRP discharges for a wide range of gas pressure and temperature $(0.1-1 \mathrm{bar}$ and $300-1500 \mathrm{~K}$ respectively). For the plane to plane electrode configurations [28, 35], experiments highlighted quasi-uniform discharges, thus validating the use of $0 \mathrm{D}$ reactors. For the pin-pin configurations [21, 27], the validity of a $0 \mathrm{D}$ approach is limited to the first instants. Indeed, according to the acoustic timescale $\tau_{a}=r_{d} / a$ where $r_{d}$ is the radius discharge and $a$ the speed of sound, the discharge remains isochoric only until $300 \mathrm{~ns}$ and $2 \mu \mathrm{s}$ in the conditions of [21] and [27] respectively. As both isochoric and isobaric reactor formulations are available in CANTERA, for each experiment the formulation yielding the best results compared with experiments has been kept. These choices are in agreement with previous simulations for cases B [28], C [27, 7] and D [35]. Concerning case A for which no $0 \mathrm{D}$ simulation is available in the literature, the isochoric formulation is chosen because of the short timescale involved compared to the acoustic timescale $\tau_{a}$.

The mixture compositions are either air or air- $\mathrm{CH}_{4}$ with argon dilution in the plasma assisted ignition case of [35]. With this combination of cases, a large amount of experimental data is available such as time resolved gas temperature and species concentration or ignition times. In section 5, these data will be used to test and validate the fast and slow gas heating, the radical production and finally the coupling of the discharge with conventional combustion kinetics. Each experiment is described in more details in the following.

\subsection{Case A}

This experimental setup is presented in [21]. NRP discharges are applied in air in a $4 \mathrm{~mm}$ pin-to-pin configuration. The discharges are $10 \mathrm{~ns}$ long with an applied voltage of $5.7 \mathrm{kV}$ between the electrodes at a frequency of $10 \mathrm{kHz}$. The gas temperature was estimated through measurements of the $\mathrm{N}_{2}(\mathrm{~B}, \mathrm{C})$ rotational temperature. However, more recent work [54] shows that the rotational distribution of the excited states

\begin{tabular}{|c|c|c|c|c|}
\hline Name & Case A & Case B & Case C & Case D \\
\hline Reference & Rusterholtz et al $[21]$ & Uddi et al $[28]$ & Montello et al [27] & Aleksandrov et al [35] \\
\hline$T_{g}[\mathrm{~K}]$ & $1500-2500$ & 300 & 300 & 1330 \\
\hline$P$ & $1 \mathrm{~atm}$ & 60 Torr & 100 Torr & 0.45 atm \\
\hline Geometry & Pin-Pin & Plane & Pin-Pin & Plane \\
\hline Reactor & Isochoric & Isochoric & Isobaric & Isobaric \\
\hline Mixture & Air & Air-CH & Ar $: \mathrm{N}_{2}: \mathrm{O}_{2}: \mathrm{CH}_{4}$ \\
\hline Data & $T_{g}, \mathrm{O}, \mathrm{N}_{2}(\mathrm{~B}, \mathrm{C})$ & $\mathrm{O}$ & $T_{g}, \mathrm{~N}_{2}(\mathrm{v})$ & Ignition time \\
\hline
\end{tabular}

Table 6: Main characteristics of selected experiments. 


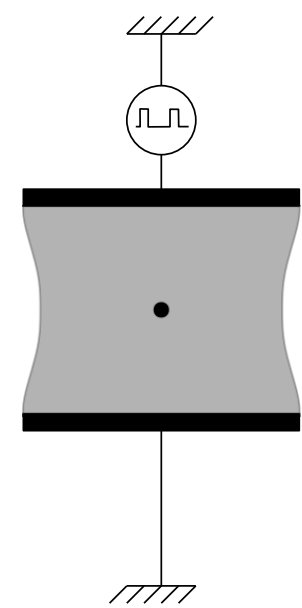

(a) Plane-Plane

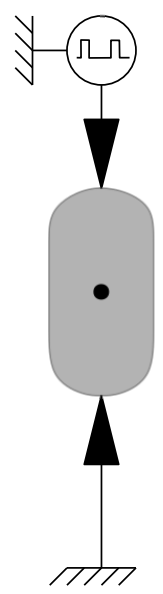

(b) Pin-Pin

Figure 3: Sketch of electrode configurations. The gray area corresponds to the discharge region. The point indicates the location modelled by the $0 \mathrm{D}$ reactor.

depends on various kinetic processes including electronic excitation, collisional quenching and rotational excitation. A detailed model was developed to account for these processes and enabled to infer the actual gas temperature from the measured rotational distributions of the $\mathrm{N}_{2}(\mathrm{~B})$ and $\mathrm{N}_{2}(\mathrm{C})$ states. After multiple pulses the temperature of the gas just before a pulse is $1500 \mathrm{~K}$ with a temperature rise of about $900 \mathrm{~K}$ in 20 ns. Optical measurements allow access to electron, nitrogen electronic states $\left(\mathrm{N}_{2}(\mathrm{~B}), \mathrm{N}_{2}(\mathrm{C})\right)$ and atomic oxygen densities. At the end of the discharge around $50 \%$ of oxygen is dissociated and the energy of the discharge is $E_{d}=670 \pm 50 \mu \mathrm{J}$ with $35 \%$ of this energy used for dissociation of $\mathrm{O}_{2}$ and $21 \%$ for gas heating.

For the CANTERA 0D simulations, the reduced electric field is taken from experimental measurements [21] while the electron density at the center of the discharge is taken from a $1 \mathrm{D}$ simulation [20]. Initially, the mixture composition is $\mathrm{N}_{2}: \mathrm{O}_{2}: \mathrm{O}: 77.4: 18.6: 4$ accounting for $\mathrm{O}_{2}$ dissociation from previous discharges.

\subsection{Case $B$}

This experiment is presented in [27]. NRP discharges are studied in plane-to-plane and pin-to-pin geometries and the focus is made on vibration populations of nitrogen. The discharges are either applied in burst mode (40 to 150 pulses) in the plane-to-plane configuration or in mono-pulse mode in the pin-to-pin configuration. It is found that in these conditions up to $50 \%$ of the discharge energy is stored into nitrogen vibrational modes. The initial temperature and pressure are $T_{0}=300 \mathrm{~K}$ and $p_{0}=100$ Torr respectively. The discharges are approximately $100 \mathrm{~ns}$ long. In this work, only the pin-to-pin configuration has been simulated. Smooth electron density and reduced electric field profiles from [27] are imposed in the 0D simulations.

\subsection{Case $C$}

The experiment described in [28] contains two planar electrodes in a rectangular geometry that produce NRP discharges in pure air and $\mathrm{CH}_{4}$-air mixtures at $300 \mathrm{~K}$ and 60 Torr. The pulses are $25 \mathrm{~ns}$ long and can be applied in single mode or in burst mode, in which case from 2 to 100 pulses are applied at $100 \mathrm{kHz}$. Measurements of atomic oxygen after the discharges are given as well as simulation results.

The simulations of [28] have been made with a reduced electric field and an electron density of Gaussian shape with a $20 \mathrm{~ns}$ FWHM (Full Width at Half Maximum). The peak reduced electric field is given at 247 $\mathrm{Td}$ and the peak electron density is chosen to satisfy the peak atomic oxygen mole fraction in air. These parameters are kept constant for the discharge in $\mathrm{CH}_{4}$-air. The same procedure has been applied in the CANTERA simulations. 


\subsection{Case D}

A shock tube setup to study ignition using NRP discharges is presented in [29]. A shock wave is initiated using a broken diaphragm and passes between two electrodes after reflection where the discharge is applied.

The simulated case, taken from [35], is characterized by an initial temperature $T_{0}=1330 \mathrm{~K}$, an initial pressure $P_{0}=0.45$ bar and an initial composition Ar: $\mathrm{N}_{2}: \mathrm{O}_{2}: \mathrm{CH}_{4}-80: 15: 4: 1$. The electric field is deduced from the measurements of the electric potential at two different locations. As the discharge is modelled in a 0D framework it is necessary to impose the electron density profile during the pulses which is deduced from the discharge energy density given in [35].

\section{Validation of the mechanisms}

0D simulations performed with the plasma-assisted combustion mechanism of Section 3 are now compared with the experimental results for the four configurations described in Section 4. Each experiment allows to validate one or more aspects of the chemistry: gas heating, radical production and ignition time.

\subsection{Fast gas heating}

The NRP discharges of Case A [21] produce fast and intense gas heating during the first tens of nanoseconds. The temperature rise is used to assess the quality of the three models of fast gas heating presented in Section 3.2. In addition to these models, simulation has been performed using the kinetic mechanism of The Ohio State University (TOSU) [7, 30]. Simulation and experimental results are shown in Fig. 4, along with previous simulation results of Popov [20,44]. In this figure, only the GRI 3.0 results are shown for readability since similar conclusions apply to the Konnov mechanism.

In Fig.4, while Models 2 and 3 are close, a $300 \mathrm{~K}$ temperature difference is observed with Model 1 after $60 \mathrm{~ns}$ which corresponds to $\approx 30 \%$ of the gas temperature increase. Both Models 2 and 3 are in good agreement with the measurements, hence other measured quantities must be used to differentiate them. The TOSU mechanism yields a gas temperature increase similar to models 2 and 3 . In the work of Popov 2016 [44], the model developed in [20] has been updated to account for quenching reactions of electronically excited nitrogen by atomic oxygen. Despite gas temperature prediction improvements, a loss of accuracy on atomic oxygen production induced by this quenching is shown in the next section.

Additional information was obtained in the experiment thanks to a secondary reflected pulse at $t=270 \mathrm{~ns}$ as shown in Fig. 4. This pulse was strong enough to efficiently stimulate the $\mathrm{C}$ states of $\mathrm{N}_{2}$ allowing an estimation of its rotational temperature. At the very beginning of this pulse, recent work [54] inferred a gas temperature of $3110 \mathrm{~K} \pm 200 \mathrm{~K}$ from the excited state $\mathrm{C}$ rotational temperature, indicating a significant gas temperature increase of about $600 \mathrm{~K} \pm 200 \mathrm{~K}$ from the end of the first pulse. With 0D simulations, the gas temperature ranges between 2900 and $3300 \mathrm{~K}$ depending on the model used, Model 1 staying approximately $200 \mathrm{~K}$ lower than the others. However, at a high temperature of about $T=2500 \mathrm{~K}$, the compression wave formed by the fast gas heating during the first pulse can not be neglected to analyze the results of the second pulse. Indeed, the acoustic timescale $\tau_{\mathrm{a}}$ is of the order of $200 \mathrm{~ns}$ in a volume of size $225 \mu \mathrm{m}$ and a speed of sound $a=\sqrt{\gamma R T_{g} / M} \simeq 1000 \mathrm{~m} \mathrm{~s}^{-1}$. This rapid gas expansion is responsible for gas temperature decrease, which is a sign that gas temperature should be even higher than the one predicted by Models 2 and 3. However, the 0D model is not able to accurately estimate the density change resulting from the compression wave. Hence the reduced electric field can not be computed so that the pulse reflection was not included in our 0D simulation. Therefore the simulated temperature stays flat contrary to the experimental measurements. The gas dynamics effects could be analyzed in further works using 1D or 2D simulations.

\subsection{Radical production}

Radical production is another important characteristic of the discharge studied in the experiment of Case A [21]. The time evolution of $\mathrm{O}\left({ }^{3} \mathrm{P}\right)$ density has been measured using Two-Photon Absorption Laser Induced Fluorescence (TALIF) technique during the pulse and the afterglow. The atomic oxygen from CANTERA simulations is displayed in Fig. 5 for the different models studied. For the same reasons as in the fast gas heating study, only the results for GRI 3.0 mechanism is shown. Models 1 to 3 yield satisfactory results when 


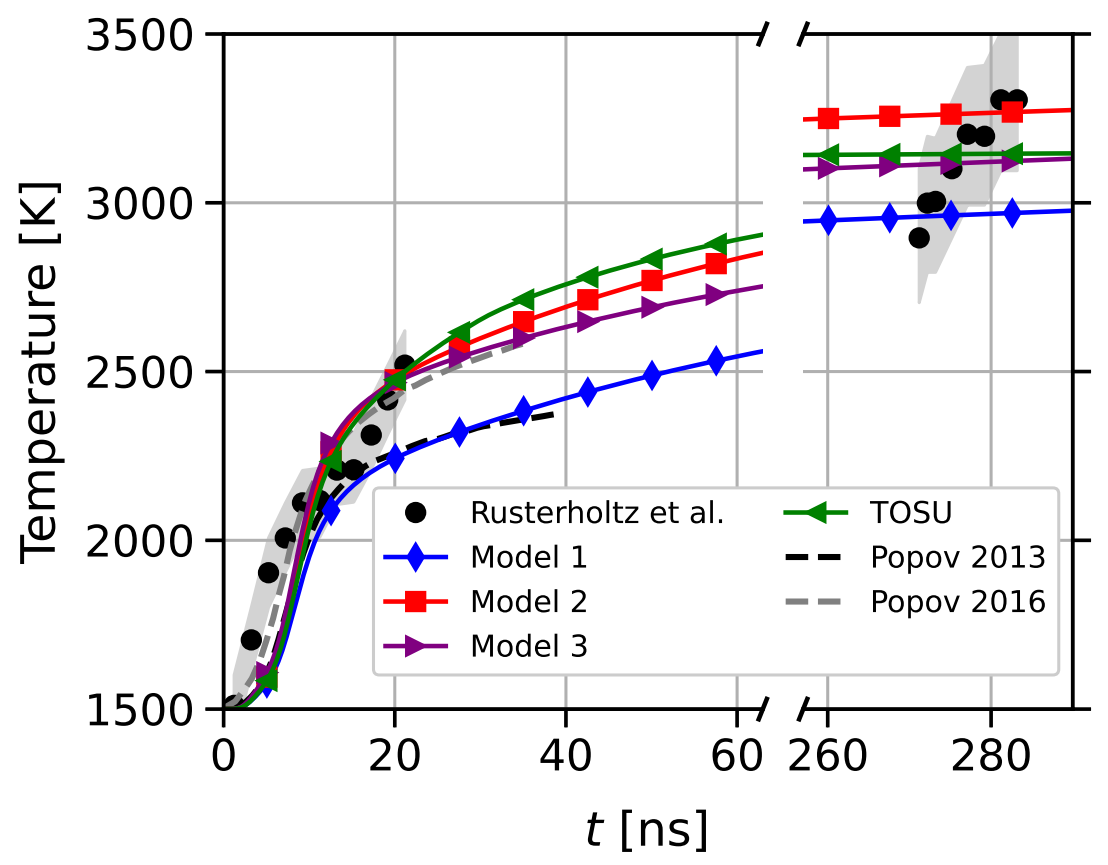

Figure 4: Gas temperature time evolution for Case A [21] using the different fast gas heating models of Section 3 and TOSU mechanism against experimental measurements (point) [21] and reference simulations (dashed: Popov 2013 [20], Popov 2016 [44]). The filled areas correspond to the experimental uncertainties of [21].

compared with experimental measurements [21] and Popov's simulation [20]. Model 3 exhibits a slighlty higher $\mathrm{O}$ production of $\sim 8 \%$ than Model 1 which seems to be in better agreement with the experimental results. However, the TOSU mechanism [7] underestimates the atomic oxygen by approximately $30 \%$. This is attributed to the quenching reaction of $\mathrm{N}_{2}{ }^{*}$ with $\mathrm{O}\left({ }^{3} \mathrm{P}\right)$ atoms (Eq. (R11)) which occurs with a very high rate. The addition of this reaction in Model 1 leading to Model 4 of Fig. 5 strongly disturbs the atomic oxygen production. This observation questions the effectiveness of reaction (R11) in our conditions.

$$
\mathrm{N}_{2}{ }^{*}+\mathrm{O}\left({ }^{3} \mathrm{P}\right) \longrightarrow \mathrm{NO}+\mathrm{N}\left({ }^{2} \mathrm{D}\right) \quad k=3 \times 10^{-10} \mathrm{~cm}^{3} \mathrm{~s}^{-1}
$$

Case B [28] setup monitors atomic oxygen decay after a discharge in both air and methane-air mixtures [28]. Konnov and GRI plasma mechanisms using Model 3 give satisfactory results concerning the rate of decay of atomic oxygen compared with experimental results and reference simulations as shown in Fig. 6 . In pure air, the difference between the two combustion mechanisms is due to the different rates used for $\mathrm{O}_{3}$ chemistry. Atomic oxygen decay in methane-air mixtures are similar using both mechanisms.

\subsection{Slow gas heating}

Slow gas heating is the result of the relaxation of vibrationally excited nitrogen molecules. The detailed simulation using VIB. 1 model on the Montello experiment yields good results for the gas temperature (Fig. 7a) as well as for the vibrational populations (Fig. 7b) over time irrespective of the combustion mechanism. The $\mathrm{VV} \mathrm{N} \mathrm{N}_{2}-\mathrm{N}_{2}$ and $\mathrm{VT} \mathrm{N}_{2} \mathrm{O}$ are thus the main vibrational relaxation channels in air. The simpler VIB. 2 model shows good agreement with the detailed model for the gas temperature in Fig. 7a, validating the method and the relaxation times considered. This approach is able to drastically reduce the number of species in the mechanism and must be considered as a valuable option for multi-dimensional works. For these reasons VIB. 2 is kept for all other calculations. 


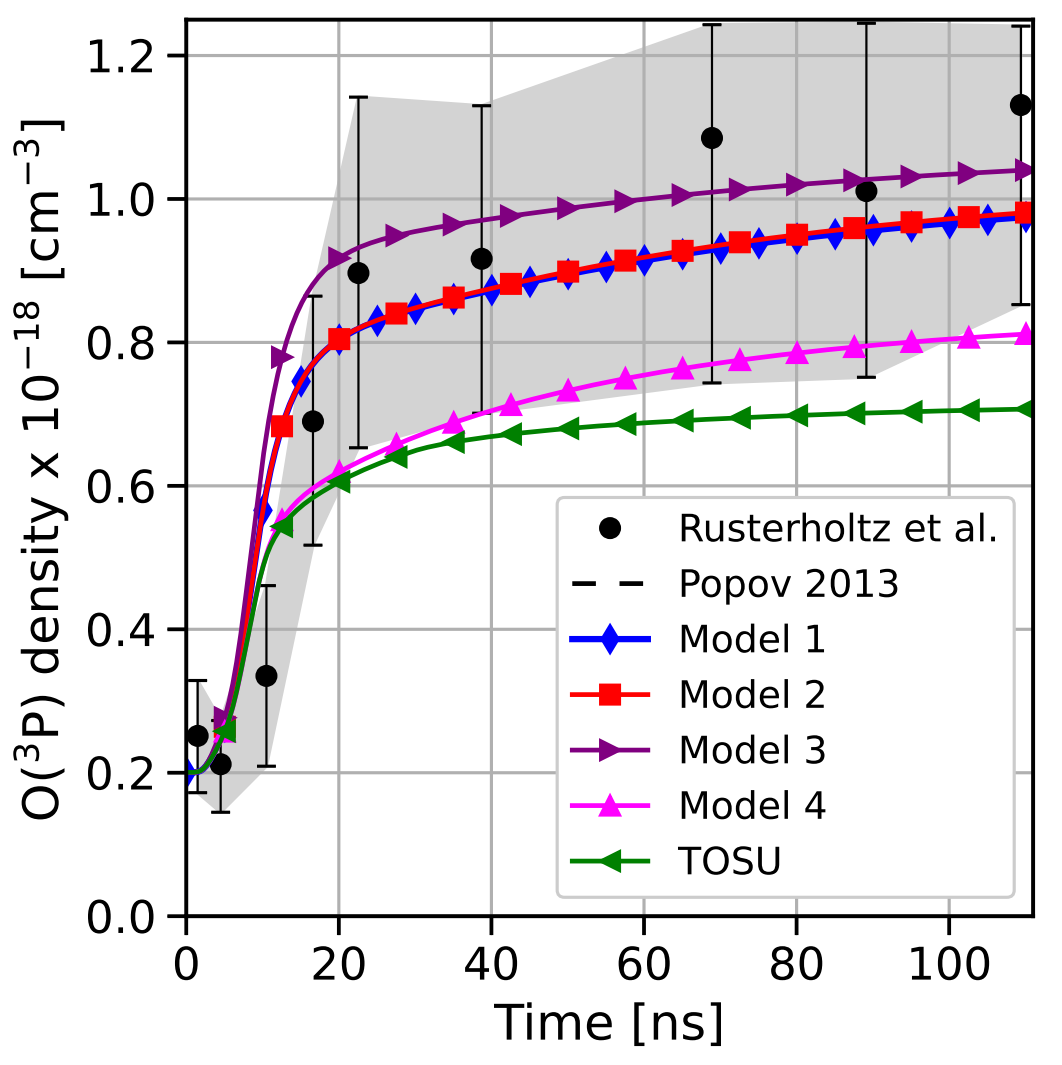

Figure 5: Time evolution of atomic oxygen density for Case A [21] using different fast gas heating model against experimental measurements (point) [21] and reference simulations (dashed line) [20]. The filled areas correspond to the experimental uncertainties. 


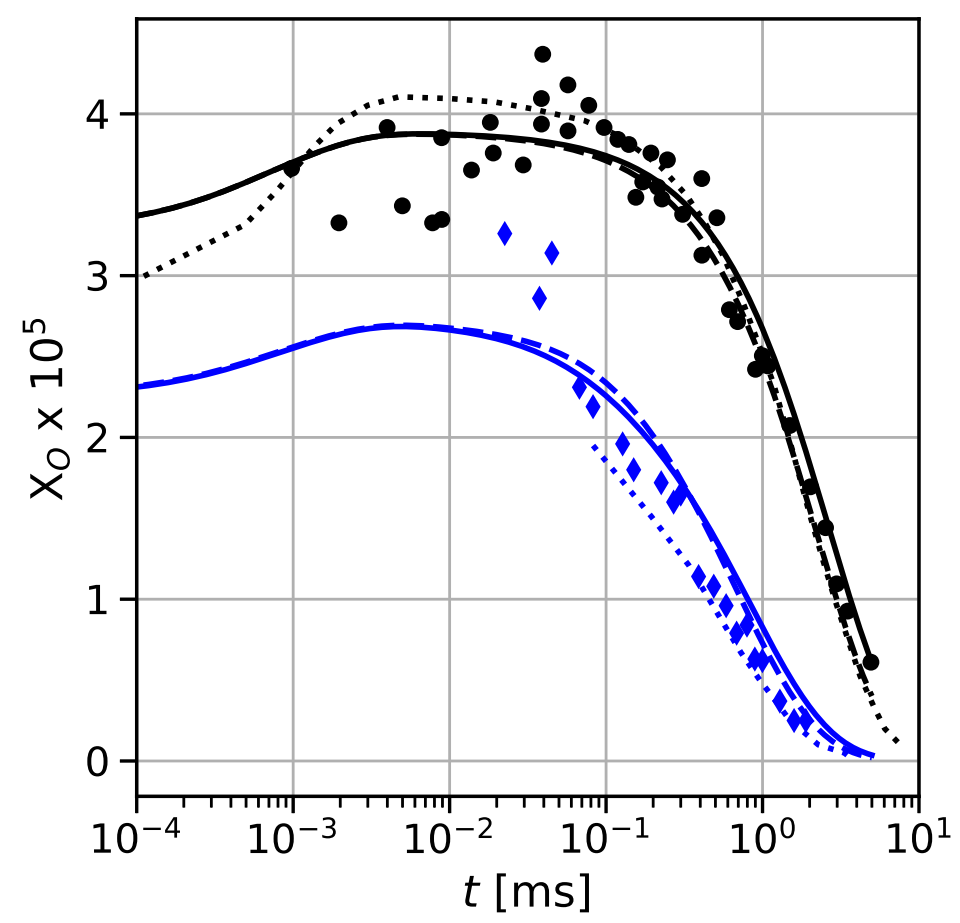

Figure 6: Time evolution of atomic oxygen mole fraction for Case B [28] using Model 3 along with GRI 3.0 (solid) or Konnov (dashed) mechanisms. Measurements (point) [28] and reference simulations (dotted) [28] are also given for comparison. Black and blue colors are respectively used for air and air-methane cases.

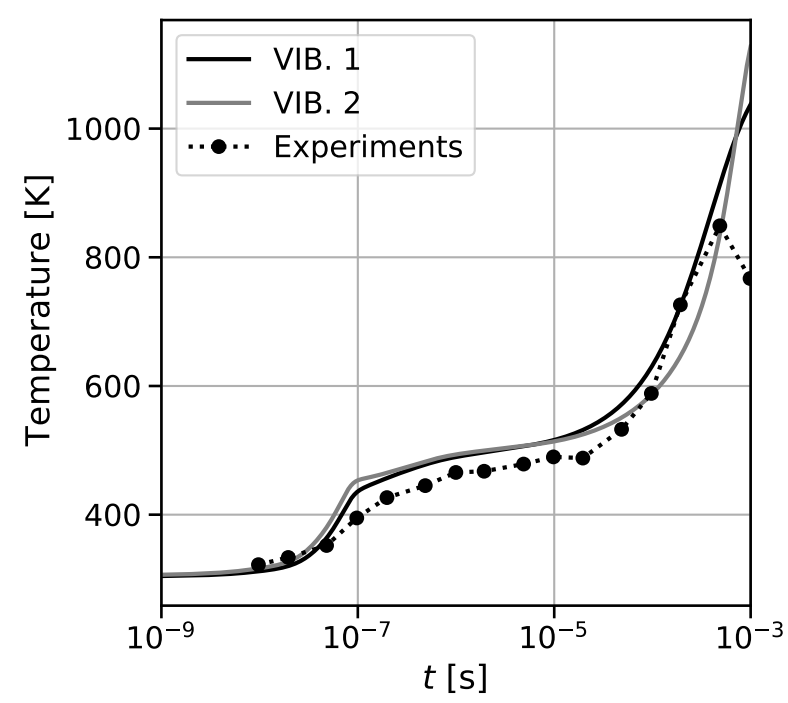

(a) Gas temperature

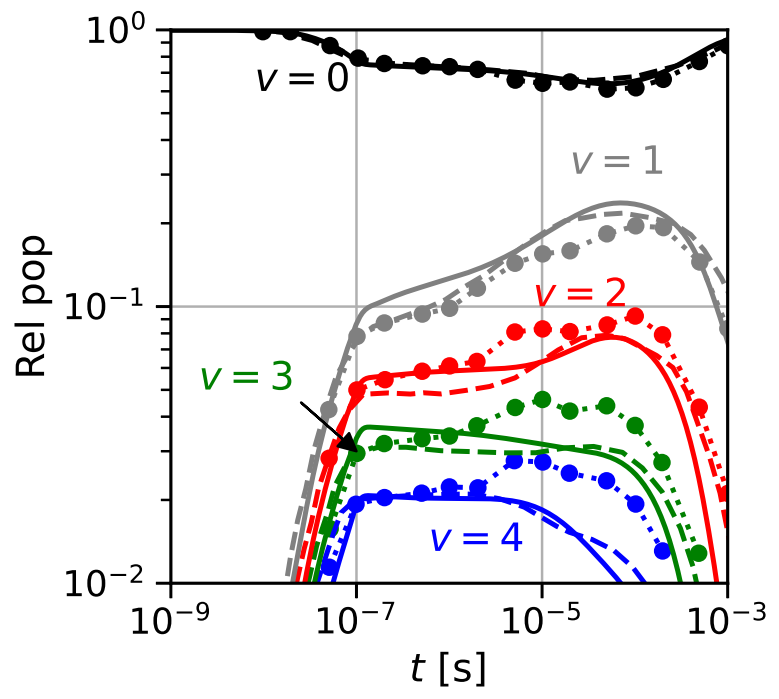

(b) $\mathrm{N}_{2}(v)$

Figure 7: Comparison of vibrational model on Case C [27] (a) gas temperature (solid, black and gray for simulation) against experimental measurements (point-dotted); (b) vibrational populations over time, $v=(0,1,2,3,4)$ correspond respectively to black, grey, red, green, blue for VIB. 2 model (solid), experimental measurements [27](point-dotted) and reference simulation [7] (dashed). 


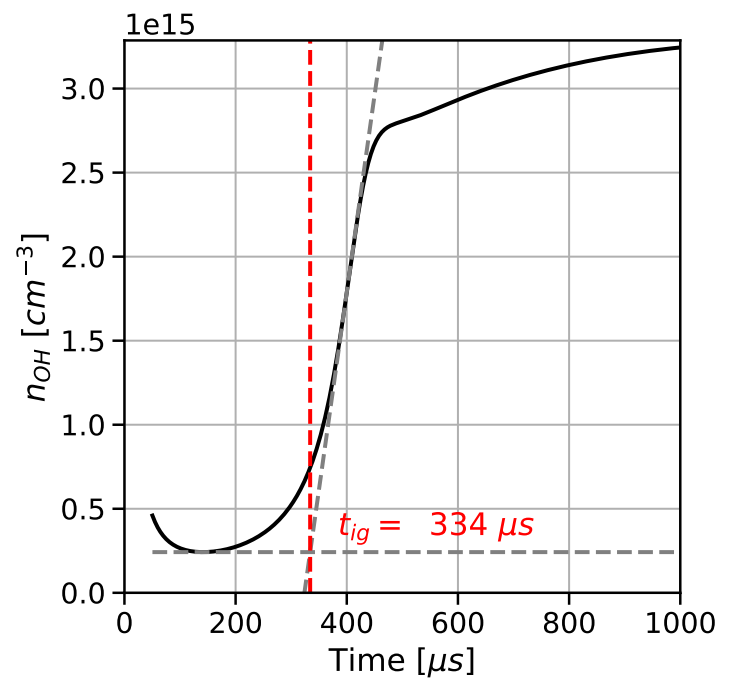

(a)

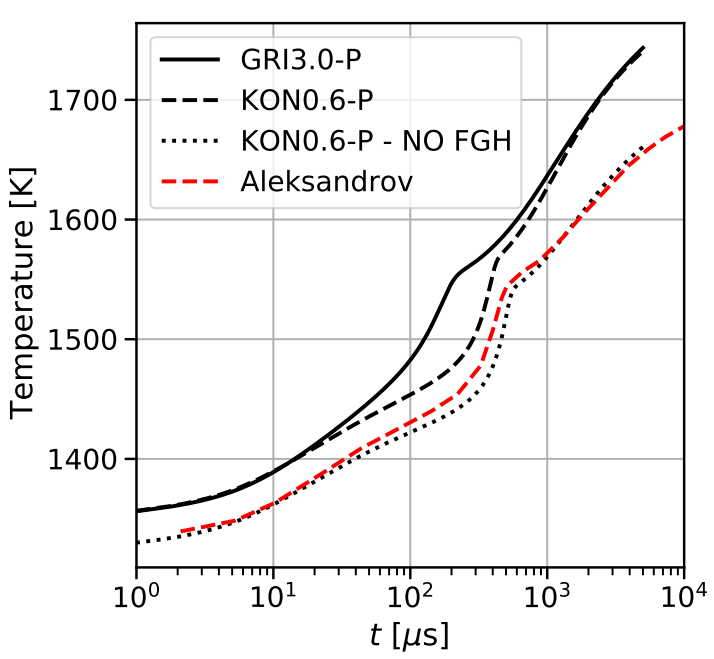

(b)

Figure 8: Results of Case D [35] (a) ignition time delay for the simulation using Konnov mechanism and (b) gas temperature.

\subsection{Ignition}

In case D, the discharge used [29] is characterized by a combination of radical production and fast gas heating promoting the ignition process. The gas heating during the discharge remains relatively low which leads to a gas temperature increase of about $100 \mathrm{~K}$. The ignition delay time $\tau_{\text {ig }}$ measured experimentally is compared with the one extracted from the simulation using the same procedure based on the $\mathrm{OH}$ mole fraction. $\tau_{\text {ig }}$ is defined at the intersection of two $\mathrm{OH}$ density tangents: one at the minimum value and the other at the inflection point during the sharp increase corresponding to the ignition process. This method is described in Fig. 8a. The ignition delay times obtained for the different combustion mechanisms are given in Tab. 7. A very good agreement with the experimental value $\tau_{\text {ig }}^{\exp }=376 \mu \mathrm{s}[29]$ is found for the case using the Konnov mechanism. The case using the GRI-3.0 mechanism exhibits a 50\% lower ignition time compared to the Konnov mechanism, which is consistent with the preliminary study of ignition delay time performed in Section 3.4. An additional simulation, referred to as "NO FGH", was performed without gas heating during the discharge phase (i.e. $t \leq 1 \mu \mathrm{s}$ ) as done in [35]. In that case, the ignition delay time increases to $448 \mu \mathrm{s}$ showing the importance of accounting for gas heating effect during the discharge.

\begin{tabular}{|c|c|c|c|c|}
\hline$\tau_{\text {ig }}$ & $X_{\mathrm{O}}$ & $X_{\mathrm{H}}$ & $X_{\mathrm{CH} 3}$ & Reference \\
\hline $332 \mu \mathrm{s}$ & $2.79 \times 10^{-3}$ & $2.7 \times 10^{-4}$ & $2.47 \times 10^{-4}$ & {$[35]$} \\
$135 \mu \mathrm{s}$ & $3.43 \times 10^{-3}$ & $3.06 \times 10^{-3}$ & $5.94 \times 10^{-4}$ & GRI 3.0 (This work) \\
$334 \mathrm{\mu s}$ & $3.14 \times 10^{-3}$ & $2.67 \times 10^{-3}$ & $7.26 \times 10^{-4}$ & Konnov v0.6 (This work) \\
$448 \mu \mathrm{s}$ & $2.92 \times 10^{-3}$ & $2.56 \times 10^{-3}$ & $6.78 \times 10^{-4}$ & Konnov v0.6 NO FGH (This work) \\
\hline
\end{tabular}

Table 7: Ignition time and maximum values of radical mole fractions.

\section{Chemistry reduction}

The mechanisms derived above for methane-air plasma-assisted combustion are computationally heavy with respectively 100 and 226 species along with 964 and 2586 reactions for the GRI-3.0 [33] and Konnov [34] plasma mechanisms. Using such mechanisms in a multi-dimensional simulation is impossible and a reduction step must be performed to decrease the computational cost. The methodology used to reduce these mechanisms is first described in Section 6.1. The test cases used to validate the reduction process 
are then presented in Section 6.2. The resulting reduced mechanism for GRI-3.0 plasma mechanism is finally presented and evaluated in Section 6.3 in terms of computational cost and accuracy. GRI-3.0 plasma mechanism has been chosen due to its lower computational cost but the methodology also applies to any plasma assisted combustion mechanism.

\subsection{Methodology}

The methodology is the one of [15] using Directed Relation Graph with Error Propagation (DRGEP), implemented in the ARCANE code co-developed at CERFACS and Cornell University [16]. The graph relies on coefficients which are computed on a set of representative cases (reduction cases) that span the range of conditions on which the reduced mechanism will be used.

The DRGEP method was recently applied in [17], where contrary to Eq. (5) the time evolution of electron temperature $T_{e}$ is governed by:

$$
c_{v e} m_{e} n_{e} \frac{d T_{e}}{d t}=-\dot{\omega}_{e} u_{e}+\dot{\mathcal{Q}}_{p}
$$

where $n_{e}$ is the electron density, $c_{v e}$ the electron specific heat at constant volume, $\dot{\omega}_{e}$ the electron mass production rate, $u_{e}$ the electron specific internal energy and $\dot{\mathcal{Q}}_{p}$ the net energy source term which depends on $T_{e}$ and electron concentration $c_{e}$.

In this work, the reaction rate coefficients of electron impact reactions $\mathcal{B}$ and electron temperature $T_{e}$ are deduced from the EEDF (Eqs. (4)-(5)). Thus, these quantities remain unaltered as long as the EEDF remains the same. Differences could be induced by modified gas temperature or mixture composition after successive reduction steps since the EEDF depends on these quantities. However, no significant effect of that kind was observed in the cases considered here.

A major property to be preserved during the reduction process is the energy that is transferred from the discharge to the electrons and ultimately to the gas mixture. In the present model, the electron temperature is computed self-consistently with the reduced electric field, gas composition and temperature. With this approach, the discharge energy transfer to the gas mixture is preserved only if all cross-sections considered in the EEDF are associated to a reaction in the kinetic mechanism, which strongly limits the reduction. A method to relax this constraint is presented in the following.

While the set of cross-sections used to compute the EEDF is immutable, the associated reactions can be simplified. For instance, the production of an electronically excited state $\mathrm{AB}^{*}$ by electron impact reaction on a species $\mathrm{AB}$ can be replaced by an inert heat production process described in Eq. (R12). The underlying assumption is that the quenching of the excited state of a molecule does not change its formula but only transfers its excitation energy into a translational mode. For reaction Eq. (R13), the chemical effect is kept when possible by quenching the excited species $\mathrm{B}^{*}$ in the products, as done previously. In a case for which species B does not exist, the reaction reduces to Eq. (R12). Applying theses rules allows to remove excited species $\mathrm{AB}^{*}$ and $\mathrm{B}^{*}$ while keeping the total energy transfer to the gas unchanged, thus reducing the mechanism.

$$
\begin{gathered}
\mathrm{e}^{-}+\mathrm{AB} \longrightarrow \mathrm{e}^{-}+\mathrm{AB}^{*} \longrightarrow \mathrm{e}^{-}+\mathrm{AB}+\text { heat } \\
\mathrm{e}^{-}+\mathrm{AB} \longrightarrow \mathrm{e}^{-}+\mathrm{A}+\mathrm{B}^{*} \longrightarrow \mathrm{e}^{-}+\mathrm{A}+\mathrm{B}+\text { heat }
\end{gathered}
$$

\subsection{Reduction cases}

The aim of the reduced mechanism is to be used in a multi-dimensional plasma-assisted combustion simulation. The test cases on which the reduction process is based must therefore be representative of the various phenomena occuring in this type of simulation. The chosen set of reduction cases is detailed in the following and a summary can be found in Tab. 8. 


\subsubsection{Plasma and combustion}

Plasma cases are selected to validate fast gas heating and radical production of the reduced mechanism. The discharge described in [21] highlights these two effects in air while [28] allows to validate radical production in a $\mathrm{CH}_{4}$ containing mixture. In both cases, the atomic oxygen concentration is targeted and the error on the final atomic oxygen density is checked. Due to the important gas heating, the heat release is also targeted in [21] and the error on the final gas temperature is also assessed.

Canonical combustion cases and targets $\left(\mathrm{CO}, \dot{\omega}_{T}\right)$ are chosen following [16]: a 0D isochoric reactor with an initial temperature of $1000 \mathrm{~K}$ and a $1 \mathrm{D}$ flame with a fresh gas temperature of $300 \mathrm{~K}$. Both combustion cases are performed for stoichiometric $\mathrm{CH}_{4}$-air mixtures at atmospheric pressure. The error on auto-ignition delay time $\tau_{\text {ig }}$ is checked on the $0 \mathrm{D}$ case while the laminar flame speed $S_{L}$ and maximum temperature $T_{g}^{\max }$ are assessed on the 1D flame case.

Finally, the plasma-combustion coupling is assessed on the case of single pulse plasma-assisted ignition of [35]. For these 0D combustion and plasma cases, the targets are: O, CO and $\dot{\omega}_{T}$. The error on the ignition delay time $\tau_{\text {ig }}$ is used to validate the reduced mechanism.

\subsubsection{Charged species dynamics}

In all the studied cases A to D used so far in this work, the time evolution of the electron density is imposed. Consequently, electroneutrality must be imposed and then the growth and decay of charged species are not monitored by reduction cases of Section 6.2.1. They are crucial in multi-dimensional simulations as they control the discharge propagation $[55,56,57]$. A simple reference test-case without an imposed electron density profile, referred to as Plasma Dynamics, is therefore included to reproduce the net ionization rate and plasma decay phase.

For this case, a $12 \mathrm{~ns}$ pulse with constant reduced electric field $E / N=200 \mathrm{Td}$ is used to mimic a discharge leading to a peak electron density of $\approx 1 \times 10^{14} \mathrm{~cm}^{-3}$ as in [56]. The plasma decay is simulated up to $10 \mu \mathrm{s}$, which is representative of a $100 \mathrm{kHz}$ repetition frequency of an NRP discharge. These are typical parameters used experimentally for NRP discharges [53, 21, 58] The initial mixture is a stoichiometric methane-air mixture at $1000 \mathrm{~K}$ and atmospheric pressure.

The time evolution of electron and ion density obtained with the GRI-3.0 plasma mechanism developed in this work is shown in Fig. 9. An increase of charged species density is observed during the first $12 \mathrm{~ns}$ followed by a plasma decay phase. Electron density is considered as the target for DRGEP coefficients and the error on the maximum value of electron density $n_{e}^{\max }$ and its final value $n_{e}^{\text {end }}$ is systematically checked after the removal of a species.

\begin{tabular}{|c|c|c|}
\hline Cases & Targets & Errors \\
\hline Case A [21] & $\mathrm{O}, \dot{\omega}_{T}$ & $T_{g}(10 \%), n_{\mathrm{O}}^{\text {end }}(10 \%)$ \\
Case C [28] & $\mathrm{O}$ & $n_{\mathrm{O}}^{\text {end }}(10 \%)$ \\
Case D [35] & $\mathrm{O}, \mathrm{CO}, \dot{\omega}_{T}$ & $\tau_{\text {ig }}(10 \%)$ \\
Plasma Dynamics & $\mathrm{e}^{-}$ & $n_{e}^{\max }(5 \%), n_{e}^{\text {end }}(25 \%)$ \\
Auto-ignition & $\mathrm{CO}, \dot{\omega}_{T}$ & $\tau_{\text {ig }}(5 \%)$ \\
1D flame & $\mathrm{CO}, \dot{\omega}_{T}$ & $s_{L}(5 \%), T_{g}^{\max }(1 \%)$ \\
\hline
\end{tabular}

Table 8: Summary of targets and errors used in the reduction process.

\subsection{Results}

The reduction was performed starting from the GRI 3.0 mechanism updated with our plasma mechanism using the simplified vibrational model VIB. 2 resulting in a detailed mechanism composed of 100 species and 950 reactions. The reduction performed with ARCANE led to a mechanism of 47 species and 429 reactions. Species included in the reduced mechanism are listed in Tab. 9: 28 species come from the GRI 3.0 mechanism while 19 species are kept from the plasma mechanism. A more detailed comparison of reduced and detailed mechanisms in the different reduction cases can be found in the supplementary materials S1. 


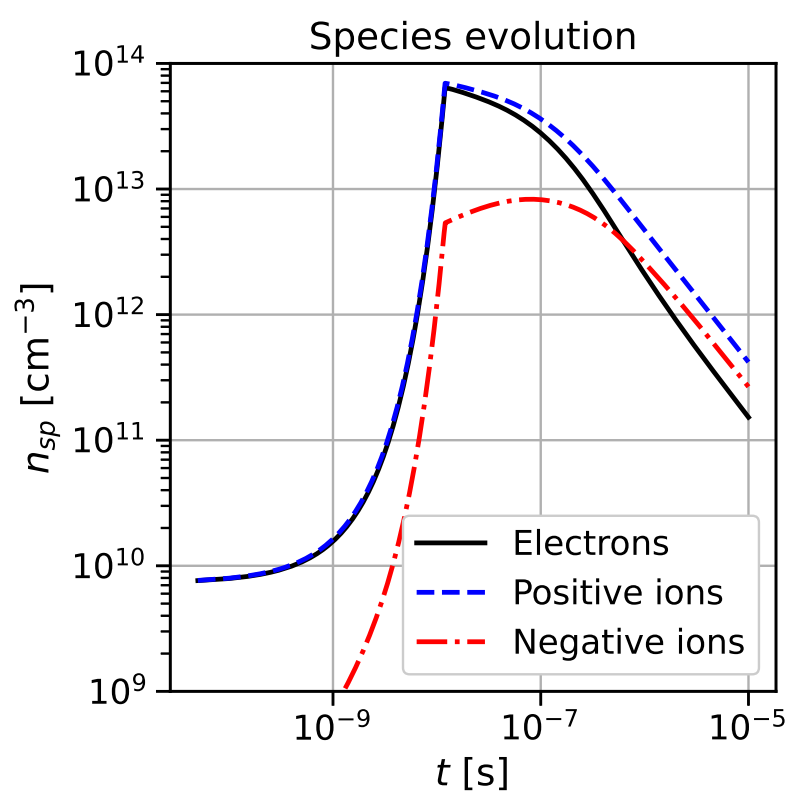

Figure 9: Time evolution of electron and ion density for Plasma Dynamics case using the detailed mechanism.

\begin{tabular}{|c|c|}
\hline & Species \\
\hline Combustion & $\mathrm{O}, \mathrm{O}_{2}, \mathrm{H}, \mathrm{OH}, \mathrm{H}_{2}, \mathrm{HO}_{2}, \mathrm{H}_{2} \mathrm{O}_{2}, \mathrm{CH}, \mathrm{CO}, \mathrm{CH}_{2}, \mathrm{HCO}, \mathrm{CH}_{2}(\mathrm{~S})$ \\
& $\mathrm{CH}_{3}, \mathrm{CH}_{2} \mathrm{O}, \mathrm{CH}_{4}, \mathrm{CO}_{2}, \mathrm{CH}_{3} \mathrm{O}, \mathrm{CH}_{3} \mathrm{OH}, \mathrm{C}_{2} \mathrm{H}_{4}, \mathrm{C}_{2} \mathrm{H}_{5}, \mathrm{C}_{2} \mathrm{H}_{6}$ \\
& $\mathrm{H}_{2} \mathrm{O}, \mathrm{N}_{2}, \mathrm{AR}, \mathrm{N}, \mathrm{NO}, \mathrm{NO}_{2}, \mathrm{H}_{2} \mathrm{CN}$ \\
\hline Plasma & $\mathrm{e}^{-}, \mathrm{N}_{2}{ }^{+}, \mathrm{O}_{2}{ }^{+}, \mathrm{CH}_{4}{ }^{+}, \mathrm{CH}_{3}{ }^{+}, \mathrm{AR}^{+}, \mathrm{NO}^{+}, \mathrm{O}^{-}, \mathrm{O}_{2}{ }^{-}$ \\
& $\left.\mathrm{N}_{2}(\mathrm{~A}), \mathrm{N}_{2}(\mathrm{~B}), \mathrm{N}_{2}(\mathrm{a}), \mathrm{N}_{2}(\mathrm{C}), \mathrm{N}^{2} \mathrm{D}\right), \mathrm{O}_{2}\left(\mathrm{a}_{1}\right)$ \\
& $\mathrm{O}\left({ }^{1} \mathrm{D}\right), \mathrm{O}\left({ }^{1} \mathrm{~S}\right), \mathrm{O}_{3}, \mathrm{AR}^{*}$ \\
\hline
\end{tabular}

Table 9: Species kept in the reduced mechanism using the cases of Tab. 8.

Another reduction considering only 0D auto-ignition and 1D flame cases (i.e. without plasma cases) was also performed for comparison. In that case, five other species of the GRI 3.0 mechanism $\left(\mathrm{CH} \mathrm{CH}_{3} \mathrm{OH}\right.$, $\mathrm{N}, \mathrm{NO}_{2}$ and $\mathrm{H}_{2} \mathrm{CN}$ ) are removed. This highlights the importance of new chemical paths in plasma-assisted combustion and validates the reduction strategy including both plasma and combustion chemistries.

The reduction procedure adopted here keeps the effective electron temperature almost unchanged as shown in Fig. 10a contrary to what was observed in [17]. This is a consequence of the use of an EEDF solver within the plasma reactors in our simulations. As pointed out previously, it must be verified that the energy transferred from electrons to heavy molecules is preserved during the reduction. In Figure 10b, the total energy has been split into chemical, heating, vibrational and excitation channels to precisely identify the potential changes caused by the reduction. While chemical and vibrational energies remain unchanged, the heating energy slightly increases to compensate for a decrease in the excitation energy. This is a consequence of the procedure described by reactions (R12) and (R13). The total energy transferred from the electrons to the gas in the Case A [21] is well reproduced by the reduced mechanism with a final error lower than $0.2 \%$.

The reliability of the reduced mechanism has been also evaluated outside of the reduction conditions. An energy density of $8 \times 10^{6} \mathrm{~J} \mathrm{~m}^{-3}$ is deposited in a single pulse at a constant reduced electric field between 150 and $300 \mathrm{Td}$ to ignite a mixture initially at $T_{g}=300 \mathrm{~K}, P=1 \mathrm{~atm}$ and equivalence ratio $\phi=1$. Simulations have been performed in a $\mathrm{CH}_{4}$-air mixture and with $80 \%$ argon dilution. The auto-ignition delay times for detailed and reduced mechanisms along with relative errors are depicted in Fig. 11. In the argon diluted case shown in Fig. 11a, the error on the ignition delay time remains lower than $10 \%$ for a large range of reduced electric field. This error is particularly low from 150 to $200 \mathrm{Td}$ where most of the reduction cases 


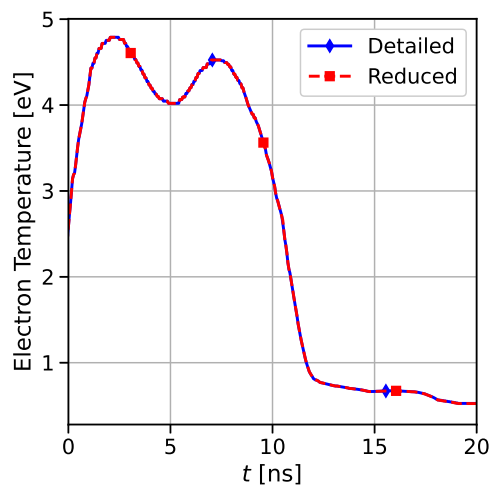

(a)

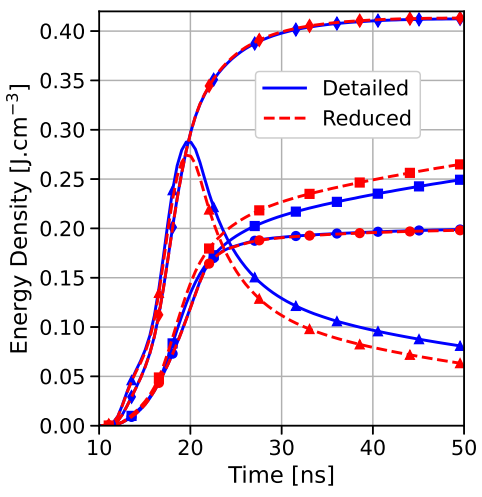

(b)

Figure 10: Comparison of the detailed and reduced mechanisms on (a) the effective temperature of the electrons (Case A) and (b) the discharge energy transfer in different channels (Case A) ( $\Delta$ Electronic, $\bullet$ Vibration, $\boldsymbol{\square}$ Heat, $\bullet$ Chemical).

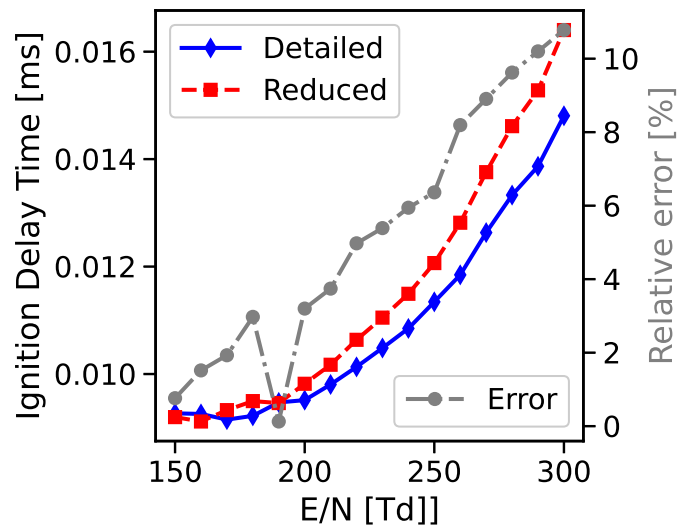

(a) $\mathrm{Ar}: \mathrm{N}_{2}: \mathrm{O}_{2}: \mathrm{CH}_{4}-80: 14.3: 3.8: 0.19$

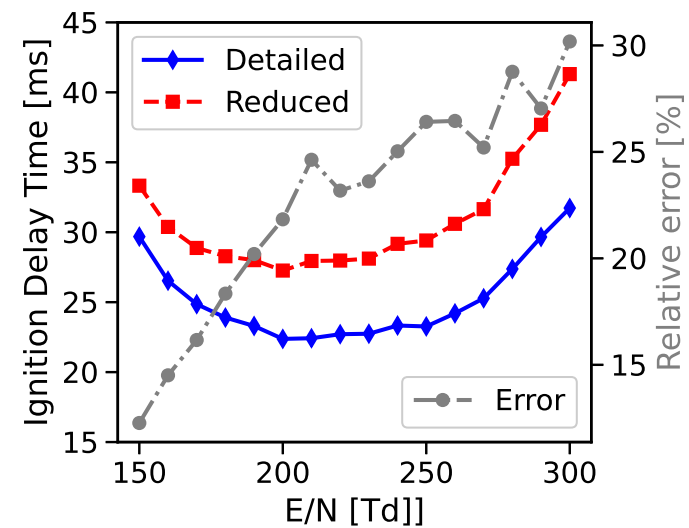

(b) $\mathrm{N}_{2}: \mathrm{O}_{2}: \mathrm{CH}_{4}-71.5: 19: 9.5$

Figure 11: Comparison of detailed and reduced mechanisms on plasma-assisted ignition delay times at various reduced electric fields for (a) argon dilluted mixture and (b) $\mathrm{CH}_{4}$-air mixture.

operate. For a higher reduced electric field, it is observed that the ignition delay time increases. This can be explained by the change in dominant electron-impact reactions from electronic excitation to ionization. While electronically excited species are able to efficiently produce radicals, ionized species mostly recombine which results in gas heating. The formation of active radicals is more efficient to ignite a mixture compared to heat deposition leading to smaller ignition delay times. The reduced mechanism is less accurate in the $\mathrm{CH}_{4}$-air mixture as depicted in Fig. 11b, highlighting the noticeable importance of argon dilution on plasmaassisted ignition behavior. Indeed, when argon is the dominant mixture component, most of the electron energy is transferred to $\mathrm{Ar}^{*}, \mathrm{Ar}^{+}$which then transfer their energy to the other molecules. However, in $\mathrm{CH}_{4}{ }^{-}$ air mixture, electron energy transfer is more complex as a wide variety of processes exist (i.e. vibrational excitation and different electronic states of $\mathrm{N}_{2}$ ). In Fig. 11b, the minimum ignition delay time is found around $200 \mathrm{Td}$, which corresponds to the case where electronic excitation is at its maximum. The slower ignition observed around $150 \mathrm{Td}$ and $300 \mathrm{Td}$, respectively due to an increase of vibrational and ionization energies, illustrates the efficiency of the electronic excitation.

A comparison of the reduced and detailed mechanisms on the combustion features is shown in Fig. 12. The error on the auto-ignition delay time remains lower than $5 \%$ on a large range of temperature [800-2000] $\mathrm{K}$ and equivalence ratio [0.5-1.5] as shown in Fig. 12a. Despite the use of stoichiometric conditions in the 


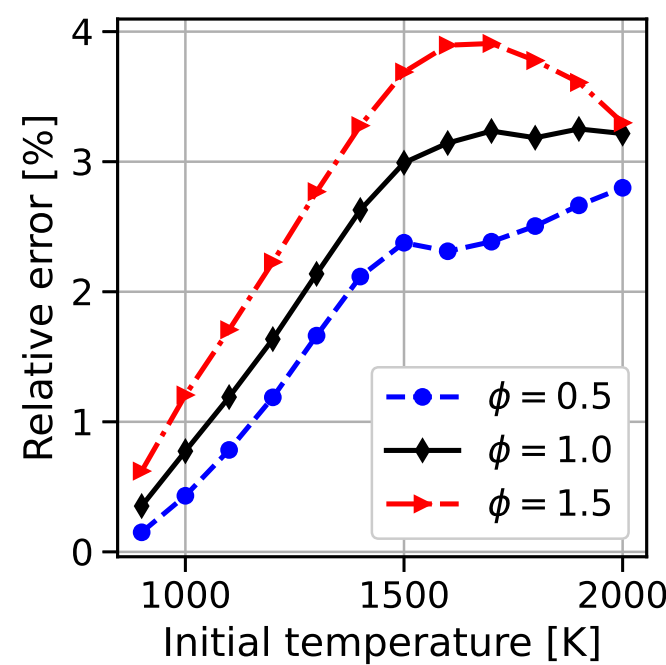

(a) Auto-ignition

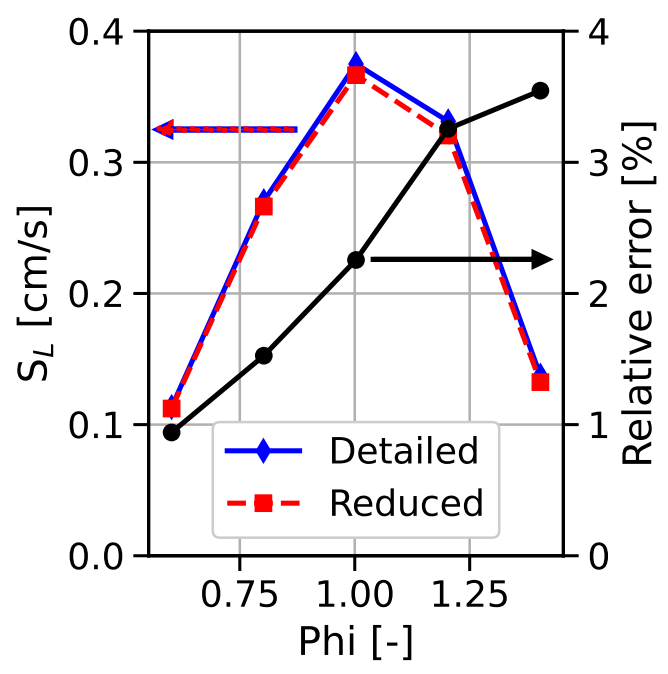

(b) $1 \mathrm{D}$ Flame

Figure 12: Comparison of detailed and reduced mechanisms: (a) auto-ignition time (relative error) and (b) laminar flame speed (value and relative error).

auto-ignition test cases during the reduction, a very good agreement is found for lean and rich mixtures. Satisfying results are also obtained for the laminar flame speed in a large range of equivalence ratio [0.6-1.4] as demonstrated in Fig. 12b.

\section{Conclusion}

In this work, a consistent and detailed plasma mechanism has been derived from [18, 22, 23] following an incremental methodology. After construction of the plasma chemistry, combustion is added considering methane as a fuel using the GRI-3.0 [33] and Konnov v0.6 [34] mechanisms. Common reactions between plasma and combustion chemistries are treated carefully to yield plasma assisted combustion mechanisms.

These mechanisms have been tested on zero-dimensional reactors using Cantera [31] with a two-temperature model incorporating the resolution of the EEDF [25, 32]. The focus has been made on three aspects of the chemistry: fast gas heating, slow gas heating and radical production.

To validate those three aspects, four experiments have been chosen [21, 27, 28, 35]. Temperature measurements in [21, 27] validate the fast gas heating reactions of the chemistry. The temporal evolution of vibrational population in [27] verifies the detailed description of vibration. Comparison with a relaxation vibrational model yields good results regarding slow gas heating allowing to reduce the size of the kinetic scheme. Finally radical production of atomic oxygen is monitored in the experiments of [21, 59] and a good agreement is found. In accordance with electron impact rates, $\mathrm{N}_{2}\left(\mathrm{a}^{1} \Pi_{\mathrm{g}}\right)$ is dominant among $\mathrm{N}_{2}\left(\mathrm{a}^{\prime 1} \Sigma_{\mathrm{u}}^{-}\right.$, $\left.\mathrm{a}^{1} \Pi_{\mathrm{g}}, \mathrm{w}^{1} \Delta_{\mathrm{u}}\right)$ and the rate of $\mathrm{O}_{2}$ dissociation by $\mathrm{N}_{2}\left(\mathrm{a}^{1} \Sigma_{\mathrm{u}}^{-}, \mathrm{a}^{1} \Pi_{\mathrm{g}}, \mathrm{w}^{1} \Delta_{\mathrm{u}}\right)$ has been chosen accordingly [46]. Compared to [20] which uses rates from [45], better results are found in [21]. Combination of these effects is tested on the plasma assisted ignition case of [29, 35]. Only on this case, noticeable differences arise between the GRI-3.0 and Konnov v0.6 plasma assisted combustion mechanisms, the latter being closer to experimental results. The mechanisms are thus valid between 300-1500 K, 0.1-1 bar and 150-300 Td in air, methane-air and argon diluted mixtures using glow and spark discharges. To the authors' knowledge, validation of plasma-assisted combustion mechanisms on such a variety of configurations and conditions is a novelty in the community.

GRI-3.0 and Konnov v0.6 plasma mechanisms contain respectively 100 and 264 species and 964 and 2860 reactions. In the purpose of using those mechanisms in multi-dimensional simulations, chemical reduction 
is necessary. Using the ARCANE code co-developed at CERFACS and Cornell University with a DRGEP reduction algorithm [15], the number of species has been reduced by a factor of 2, yielding a 47-species, 429reactions reduced mechanism from the GRI-3.0 plasma mechanism. During the reduction process, essential properties of plasma assisted combustion have been targeted. Reduction cases include real cases from experiments $[21,59,29]$ which allow to monitor the errors of the reduced mechanism against physical cases with confidence. This opens the way to reliable multi-dimensional simulations using the low-temperature plasma code AVIP [60] coupled to the combustion code AVBP [61], both developed at CERFACS.

When testing the reduced mechanisms on plasma assisted ignition in $\mathrm{CH}_{4}$-air mixtures, less than $30 \%$ error is observed on ignition delay times. This is a satisfying result since the conditions considered were not targeted within the reduction. Experimental cases of such configurations would benefit the construction of more reliable chemistries at those conditions.

\section{Acknowledgments}

This work was supported by the ANR projects PASTEC (ANR-16-CE22-0005) and GECCO (ANR-17CE06-0019). The authors thank Prof. Christophe Laux (EM2C, CentraleSupélec) for the fruitful discussions. 


\section{References}

[1] A. Starikovskiy, N. Aleksandrov, Plasma-assisted ignition and combustion, Prog. Energ. Combust. 39 (1) (2013) 61 - 110.

[2] G. Pilla, D. Lacoste, D. Veynante, C. Laux, Stabilization of a swirled propane-air flame using a nanosecond repetitively pulsed plasma, IEEE T. Plasma Sci. 36 (2008) $940-941$.

[3] A. Y. Starikovskii, N. B. Anikin, I. N. Kosarev, E. I. Mintoussov, M. M. Nudnova, A. E. Rakitin, D. V. Roupassov, S. M. Starikovskaia, V. P. Zhukov, Nanosecond-pulsed discharges for plasma-assisted combustion and aerodynamics, J. Propul. Power 24 (6) (2008) 1182-1197.

[4] C. D. Cathey, T. Tang, T. Shiraishi, T. Urushihara, A. Kuthi, M. A. Gundersen, Nanosecond plasma ignition for improved performance of an internal combustion engine, IEEE T. Plasma Sci. 35 (6) (2007) 1664-1668.

[5] S. Bozhenkov, S. Starikovskaia, A. Starikovskii, Nanosecond gas discharge ignition of $\mathrm{H}_{2}$ and $\mathrm{CH}_{4}$ containing mixtures, Combust. Flame 133 (1) (2003) $133-146$.

[6] Y. Ju, J. K. Lefkowitz, C. B. Reuter, S. H. Won, X. Yang, S. Yang, W. Sun, Z. Jiang, Q. Chen, Plasma assisted low temperature combustion, Plasma Chem. Plasma P. 36 (1) (2016) 85-105.

[7] I. V. Adamovich, T. Li, W. R. Lempert, Kinetic mechanism of molecular energy transfer and chemical reactions in low-temperature air-fuel plasmas, Philos. T. R. Soc. A 373 (2048) (2015) 20140336.

[8] A. C. DeFilippo, J.-Y. Chen, Modeling plasma-assisted methane-air ignition using pre-calculated electron impact reaction rates, Combust. Flame 172 (2016) 38-48.

[9] N. Deak, A. Bellemans, F. Bisetti, Plasma-assisted ignition of methane/air and ethylene/air mixtures: Efficiency at low and high pressures, P. Combust. Inst. 38 (4) (2021) 6551-6558.

[10] S. Yang, S. Nagaraja, W. Sun, V. Yang, Multiscale modeling and general theory of non-equilibrium plasma-assisted ignition and combustion, J. Phys. D Appl. Phys. 50 (43) (2017) 433001.

[11] T. A. Casey, J. Han, M. Belhi, P. G. Arias, F. Bisetti, H. G. Im, J.-Y. Chen, Simulations of planar non-thermal plasma assisted ignition at atmospheric pressure, P. Combust. Inst. 36 (3) (2017) 4155-4163.

[12] M. S. Bak, H. Do, M. G. Mungal, M. A. Cappelli, Plasma-assisted stabilization of laminar premixed methane/air flames around the lean flammability limit, Combust. Flame 159 (10) (2012) 3128-3137.

[13] D. Breden, L. L. Raja, C. A. Idicheria, P. M. Najt, S. Mahadevan, A numerical study of high-pressure non-equilibrium streamers for combustion ignition application, J. Appl. Phys. 114 (8) (2013) 083302.

[14] Y. Bechane, B. Fiorina, Numerical investigations of turbulent premixed flame ignition by a series of nanosecond repetitively pulsed discharges, P. Combust. Inst. 38 (4) (2021) 6575-6582.

[15] P. Pepiot, Automatic strategies to model transportation fuel surrogates, Ph.D. thesis, Stanford University (2008).

[16] Q. Cazères, P. Pepiot, E. Riber, B. Cuenot, A fully automatic procedure for the analytical reduction of chemical kinetics mechanisms for computational fluid dynamics applications, Fuel 303 (2021) 121247.

[17] A. Bellemans, N. Kincaid, N. Deak, P. Pepiot, F. Bisetti, P-DRGEP: a novel methodology for the reduction of kinetics mechanisms for plasma-assisted combustion applications, P. Combust. Inst. 38 (4) (2021) 6631-6639.

[18] N. Popov, Fast gas heating in a nitrogen-oxygen discharge plasma: I. kinetic mechanism, J. Phys. D Appl. Phys., Volume 44, Issue 28 (2011).

[19] V. Guerra, A. T. del Caz, C. D. Pintassilgo, L. L. Alves, Modelling $\mathrm{N}_{2}-\mathrm{O}_{2}$ plasmas: volume and surface kinetics, Plasma Sources Sci. T. 28 (7) (2019) 073001.

[20] N. Popov, Fast gas heating initiated by pulsed nanosecond discharge in atmospheric pressure air, Proc. AIAA (01 2013).

[21] D. Rusterholtz, D. Lacoste, G. Stancu, D. Pai, C. Laux, Ultrafast heating and oxygen dissociation in atmospheric pressure air by nanosecond repetitively pulsed discharges, J. Phys. D Appl. Phys. 46 (2013) 4010-.

[22] M. Capitelli, F. C.M., B. Gordiets, A. Osipov, Plasma Kinetics in Atmospheric Gases, Springer, Berlin, 2000.

[23] I. A. Kossyi, A. Y. Kostinsky, A. A. Matveyev, V. P. Silakov, Kinetic scheme of the non-equilibrium discharge in nitrogenoxygen mixtures, Plasma Sources Sci. T. 1 (3) (1992) 207-220.

[24] Y. Ju, W. Sun, Plasma assisted combustion: Dynamics and chemistry, Prog. Energ. Combust 48 (2015) $21-83$.

[25] G. J. M. Hagelaar, L. C. Pitchford, Solving the boltzmann equation to obtain electron transport coefficients and rate coefficients for fluid models, Plasma Sources Sci. T. 14 (4) (2005) 722-733.

[26] I. Shkurenkov, D. Burnette, W. R. Lempert, I. V. Adamovich, Kinetics of excited states and radicals in a nanosecond pulse discharge and afterglow in nitrogen and air, Plasma Sources Sci. T. 23 (6) (2014) 065003.

[27] A. Montello, Z. Yin, D. Burnette, I. V. Adamovich, W. R. Lempert, Picosecond CARS measurements of nitrogen vibrational loading and rotational/translational temperature in non-equilibrium discharges, J. Phys. D Appl. Phys. 46 (46) (2013) 464002 .

[28] M. Uddi, N. Jiang, E. Mintusov, I. Adamovich, W. Lempert, Atomic oxygen measurements in air and air/fuel nanosecond pulse discharges by two photon laser induced flourescence, in: 46th AIAA Aerospace Sciences Meeting and Exhibit, American Institute of Aeronautics and Astronautics, 2008.

[29] S. Starikovskaia, E. Kukaev, A. Kuksin, M. Nudnova, A. Starikovskii, Analysis of the spatial uniformity of the combustion of a gaseous mixture initiated by a nanosecond discharge, Combust. Flame 139 (3) (2004) $177-187$.

[30] C. Winters, Z. Eckert, Z. Yin, K. Frederickson, I. V. Adamovich, Measurements and kinetic modeling of atomic species in fuel-oxidizer mixtures excited by a repetitive nanosecond pulse discharge, J. Phys. D Appl. Phys. 51 (1) (2017) 015202.

[31] D. G. Goodwin, R. L. Speth, H. K. Moffat, B. W. Weber, Cantera: An object-oriented software toolkit for chemical kinetics, thermodynamics, and transport processes, version 2.5.1, https://www . cantera.org (2021). doi:10.5281/zenodo.4527812.

[32] A. T. del Caz, V. Guerra, D. Goncalves, M. L. da Silva, L. Marques, N. Pinhao, C. D. Pintassilgo, L. L. Alves, The LisbOn KInetics boltzmann solver, Plasma Sources Sci. T. 28 (4) (2019) 043001. 
[33] G. P. Smith, D. M. Golden, M. Frenklach, N. W. Moriarty, B. Eiteneer, M. Goldenberg, C. T. Bowman, R. K. Hanson, S. Song, W. C. Gardiner, J. V. V. Lissianski, Z. Qin, http://www.me.berkeley.edu/gri_mech/.

[34] M. L. Lavadera, C. Brackmann, A. A. Konnov, Experimental and modeling study of laminar burning velocities and nitric oxide formation in premixed ethylene/air flames, P. Combust. Inst. 38 (1) (2021) 395-404.

[35] N. L. Aleksandrov, S. V. Kindysheva, E. N. Kukaev, S. M. Starikovskaya, A. Y. Starikovskii, Simulation of the ignition of a methane-air mixture by a high-voltage nanosecond discharge, Plasma Phys. Rep. 35 (10) (2009) 867-882.

[36] PHELPS database, retrieved on July 30, 2020, www.1xcat.net/Phelps.

[37] TRINITI database, retrieved on September 14, 2020, www.lxcat.net/Triniti.

[38] HAYASHI database, retrieved on September 14, 2020, www.lxcat.net/Hayashi.

[39] IST-LISBON database, retrieved on October 19, 2020, ww. Ixcat.net/IST-Lisbon.

[40] MORGAN database, retrieved on October 6, 2020, www. lxcat.net/Morgan.

[41] W. M. Huo, T. L. Gibson, M. A. P. Lima, V. McKoy, Schwinger multichannel study of the ${ }^{2} \Pi_{\mathrm{g}}$ shape resonance in $\mathrm{N}_{2}$, Phys. Rev. A 36 (1987) 1632-1641.

[42] N. A. Popov, Investigation of the mechanism for rapid heating of nitrogen and air in gas discharges, Plasma Phys. Rep. 27 (10) (2001) 886-896.

[43] E. I. Mintoussov, S. J. Pendleton, F. G. Gerbault, N. A. Popov, S. M. Starikovskaia, Fast gas heating in nitrogen-oxygen discharge plasma: II. Energy exchange in the afterglow of a volume nanosecond discharge at moderate pressures, J. Phys. D Appl. Phys. 44 (28) (2011) 285202.

[44] N. A. Popov, Pulsed nanosecond discharge in air at high specific deposited energy: fast gas heating and active particle production, Plasma Sources Sci. T. 25 (4) (2016) 044003.

[45] L. G. Piper, Quenching rate coefficients for $\mathrm{N}_{2}$ (a'1), J. Chem. Physics 87 (3) (1987) 1625-1629.

[46] W. Marinelli, W. Kessler, B. Green, W. Blumberg, Quenching of $\mathrm{N}_{2}\left(a^{1} \pi_{g}, \mathrm{v}^{\prime}=\mathrm{o}\right)$ by $\mathrm{N}_{2}, \mathrm{O}_{2}, \mathrm{CO}, \mathrm{CO}_{2}, \mathrm{CH}_{4}, \mathrm{H}_{2}$ and Ar, J. Chem. Physics 90 (1989) 9.

[47] R. C. Millikan, D. R. White, Systematics of vibrational relaxation, J. Chem. Physics 39 (12) (1963) $3209-3213$.

[48] M. Hayashi, Electron collision cross-sections for molecules determined from beam and swarm data, Swarm Studies and Inelastic Electron-Molecule Collisions, Springer (1987).

[49] S. Heijkers, M. Aghaei, A. Bogaerts, Plasma-based $\mathrm{CH}_{4}$ conversion into higher hydrocarbons and $\mathrm{H}_{2}$ : $\mathrm{Modeling}$ to reveal the reaction mechanisms of different plasma sources, J. Phys. Chem. C 124 (13) (2020) 7016-7030.

[50] Z. Eckert, Energy transfer in non-equilibrium reacting gas flows: Applications in plasma assisted combustion and chemical gas lasers, Ph.D. thesis, the Ohio State University (2018).

[51] A. A. Konnov, On the role of excited species in hydrogen combustion, Combust. Flame 162 (10) (2015) 3755-3772.

[52] D. Z. Pai, G. D. Stancu, D. A. Lacoste, C. O. Laux, Nanosecond repetitively pulsed discharges in air at atmospheric pressure - the glow regime, Plasma Sources Sci. T. 18 (4) (2009) 045030.

[53] D. Z. Pai, D. A. Lacoste, C. O. Laux, Nanosecond repetitively pulsed discharges in air at atmospheric pressure - the spark regime, Plasma Sources Sci. T. 19 (6) (2010) 065015.

[54] A. C. Tibère-Inglesse, S. D. McGuire, C. O. Laux, Inferring the gas temperature from the rotational temperatures of $\mathrm{N}_{2}(\mathrm{~B})$ and $\mathrm{N}_{2}(\mathrm{C})$, To be submitted.

[55] A. A. Kulikovsky, Positive streamer between parallel plate electrodes in atmospheric pressure air, J. Phys. D Appl. Phys. 30 (3) (1997) 441-450.

[56] G. V. Naidis, Modelling of transient plasma discharges in atmospheric-pressure methane-air mixtures, J. Phys. D Appl. Phys. 40 (15) (2007) 4525-4531.

[57] S. Kobayashi, Z. Bonaventura, F. Tholin, N. A. Popov, A. Bourdon, Study of nanosecond discharges in $\mathrm{H}_{2}$-air mixtures at atmospheric pressure for plasma assisted combustion applications, Plasma Sources Sci. T. 26 (7) (2017) 075004.

[58] J. K. Lefkowitz, T. Ombrello, An exploration of inter-pulse coupling in nanosecond pulsed high frequency discharge ignition, Combust. Flame 180 (2017) 136-147.

[59] M. Uddi, Non-equilibrium kinetic studies of repetitively pulsed nanosecond discharge plasma assisted combustion, Ph.D. thesis, the Ohio State University (2008).

[60] L. Cheng, N. Barleon, O. Vermorel, B. Cuenot, A. Bourdon, Avip: a low temperature plasma code, arXiv preprint arXiv (2021).

[61] T. Schonfeld, M. Rudgyard, Steady and unsteady flow simulations using the hybrid flow solver AVBP, AIAA 37 (11) (1999) 1378-1385. 